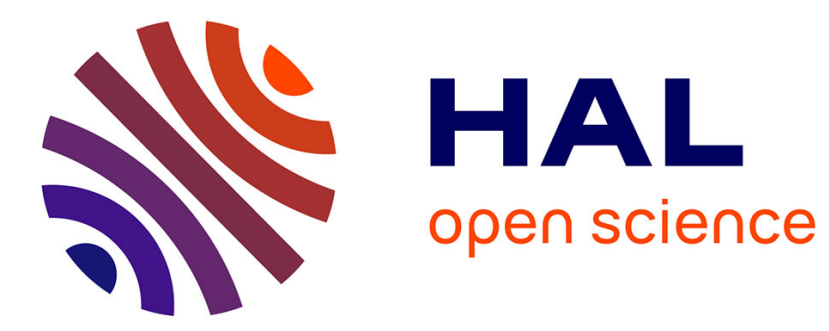

\title{
Complex Contagions and the Diffusion of Innovations: Evidence from a Small-N Study
}

\author{
Gianluca Manzo, Simone Gabbriellini, Valentine Roux, Freda Nkirote
}

M'mbogori

\section{- To cite this version:}

Gianluca Manzo, Simone Gabbriellini, Valentine Roux, Freda Nkirote M'mbogori. Complex Contagions and the Diffusion of Innovations: Evidence from a Small-N Study. Journal of Archaeological Method and Theory, 2018, 25 (4), pp.1109-1154. 10.1007/s10816-018-9393-z . hal-02187036

\section{HAL Id: hal-02187036 \\ https://hal.sorbonne-universite.fr/hal-02187036}

Submitted on 17 Jul 2019

HAL is a multi-disciplinary open access archive for the deposit and dissemination of scientific research documents, whether they are published or not. The documents may come from teaching and research institutions in France or abroad, or from public or private research centers.
L'archive ouverte pluridisciplinaire HAL, est destinée au dépôt et à la diffusion de documents scientifiques de niveau recherche, publiés ou non, émanant des établissements d'enseignement et de recherche français ou étrangers, des laboratoires publics ou privés. 
To be published in the Journal of Archaeological Method and Theory (December issue). Please note that the paper is entering the editing process. Small mistakes and typos may still exist in the present version. Please do not circulate without the authors' permission.

Title: Complex Contagions and the Diffusion of Innovations: Evidence from a small-N study

Authors: Gianluca Manzo ${ }^{1}$, Simone Gabbriellini ${ }^{2}$, Valentine Roux ${ }^{3}$, Freda Nkirote M'Mbogori ${ }^{4}$

${ }^{1}$ GEMASS (UMR 8598), CNRS \& University of Paris-Sorbonne; ${ }^{2}$ Department of Economics and Management, University of Brescia; ${ }^{3} \mathrm{CNRS}$, UMR 7055, France; ${ }^{4}$ British Institute in Eastern Africa, Kenya

Abstract: The recent literature on "complex contagions" challenges Granovetter's classic hypothesis on the strength of weak ties and argues that, when the actors' choice requires reinforcement from several sources, it is the structure of strong ties that really matters to sustain rapid and wide diffusion. The paper contributes to this debate by reporting on a small-N study that relies on a unique combination of ethnographic data, social network analysis, and computational models. In particular, we investigate two rural populations of Indian and Kenyan potters who have to decide whether adopting new, objectively more efficient and economically more attractive, technical/stylistic options. Qualitative field data show that religious sub-communities within the Indian and Kenyan populations exhibit markedly different diffusion rates and speed over the last thirty years. To account for these differences, we first analyze empirically observed kinship networks and advice networks, and, then, we recreate the actual aggregate diffusion curves through a series of empirically-calibrated agent-based simulations. Combining the two methods, we show that, while single exposure through heterophilious weak ties were sufficient to initiate the diffusion process, large bridges made of strong ties can in fact lead to faster or slower diffusion depending on the type of signals circulating in the network. We conclude that, even in presence of "complex contagions", dense local ties cannot be regarded as a sufficient condition for faster diffusion.

Keywords: ceramic techniques; innovation diffusion; weak ties; strong ties; kinship networks; complex contagions; agent-based simulations.

Authors' contribution: The article arises from a common theoretical and methodological effort. Authors were however differently involved in the specific tasks needed to reach the final product. In particular, Freda Nkirote M'Mbogori especially contributed to field investigations in Kenya; Valentine Roux especially contributed to research design and field investigations in India; Simone Gabbriellini especially contributed to qualitative data coding, modeling and simulation, and data analysis; Gianluca Manzo especially contributed to research and method design, analysis of the literature, modeling, data analysis and article writing. 


\section{Introduction}

The diffusion of innovations is a classical research area in sociology (see Strang and Soule 1998; Palloni 2001; Weynert 2002; Rogers 2003: ch. 2). In this field, as noted by Boudon (1986: 32-43, 49-50), social scientists have long been fascinated by understanding the reasons why actors may reject new practices that an external observer instead regards as beneficial. To explain the context-dependent nature of actors' rationality when innovation decisions are at stake, sociologists were very early to develop the idea that interpersonal relationships may play a crucial role in this (Ryan and Gross 1943; Coleman et al. 1957). Ties with acquaintances, friends, family members and/or colleagues, conveying information, normative models, and/or practical help, can indeed impact on actors' perceptions of the pay-offs that novelty can offer as well as on their learning opportunities, thus creating a non-linear connection between micro-level properties and macroscopic patterns of diffusion (Granovetter 1973; Valente 1999; Di Maggio and Garip 2012; Baldassarri 2015; Erikson 2017).

In this study, we pursue this network-oriented line of investigation through the comparison of two diffusion processes involving technical and stylistic innovations in the field of pottery. In particular, on the one hand, we studied male potters living in the North-west of India, who, starting in 1987, had to choose whether to continue firing their pots using open fires or to adopt a new firing technique, i.e. the kiln. On the other hand, we also studied female potters living in central Kenya, who, starting in 1997, had to decide whether to continue to produce round-based pots or to adopt a new form, i.e. flat-based pots. The comparison of these two social contexts is sociologically relevant because they contain two nested empirical puzzles whose solution leads to new insights on how social network and actors' attributes together generate macroscopic diffusion dynamics.

As to the puzzles, the first is a within-case puzzle and concerns our explananda, i.e. observed differences in the macroscopic cumulative diffusion curves within sub-groups of Indian and Kenyan potters. In particular, it is unclear why, in India, Muslim potters adopted the kiln faster and more widely than Hindu potters; similarly, in Kenya, there is no obvious explanation for why flat-based pots were adopted more rapidly and widely among "Mukurino" potters (members of the Akorino cult) compared to potters of a different religious affiliation.

The second puzzle unexpectedly arose while trying to solve the first one. It concerns our chosen explanans, i.e. family network structures characterizing Muslim-Indian, Hindu-Indian, Mukurino-Kenyan, and other-religion-Kenyan potters. Based on theoretical scholarship arguing that the diffusion of many social behaviors is likely to be faster within interconnected closely knit groups (Young 2011), our expectation was that the innovations under study should have spread 
faster and more widely within the religious sub-communities where (1) family ties can be navigated through numerous actors connecting many relatives (high reachability) and (2) relatives of two given potters also share family ties (high local redundancy). In fact we discovered that this was, to a large extent, only the case in the Indian social context; among Kenyan potters, by contrast, high reachability and local redundancy did not co-occur with rapid and greater diffusion.

The solution to this explanans-level puzzle, which in turn solves our explanandum-level enigma, gives our comparative small-n study the potential to make an important theoretical contribution to recent debates on the network-level properties that matter in facilitating the diffusion of innovations (for an overview, see Centola 2018: chs. 2 and 3). In a nutshell, according to the traditional view, "weak" ties are better able to connect otherwise disconnected parts of a social network, thus facilitating the spread of innovations. More recent scholarship contends, however, that, when contagion is "complex" (that is, a single contact is not sufficient to adopt a new behavior), high network reachability is insufficient to foster diffusion: locally dense "strong ties" - such as family or friendship relationships - are the real incubators of diffusion.

Our observations give only partial support to these hypotheses in that we found that a combination of high reachability and local redundancy does not necessarily lead to rapid diffusion. We will explain this by arguing that, when complex contagions are at stake, locally dense social ties foster diffusion provided actors who lie at the intersection of numerous social paths are able to provide high-quality advice and are deeply involved in the diffusion process. If this is not the case, locally dense strong ties will amplify low-quality signals, thus reinforcing doubts, and ultimately slowing down, rather than accelerating, diffusion. Thus theoretically our small-n study ultimately leads to a qualification of the strength-of-strong-ties thesis, effectively summarized by (Centola 2011: 1271) when he states that “(..$)$ the lack of 'wide bridges' in social networks can significantly inhibit the level of adoption in a population (...)".

We should stress that this substantive result will be achieved through a combination of several methods. First, in-depth interviews provide us with raw materials on potters' technical choices as well as on the flows of advice and the familial connections in which potters were embedded in India and Kenya. Second, after turning the potters' own narratives into quantitative relational data, we will rely on social network analysis to measure the relevant network-level properties potentially correlating with rapid innovation diffusion. Third, to shed light on the seemingly inconsistent results of the quantitative analysis of family networks by religious sub-groups, we will use the data on potters' technical skills that we produced through in-field experiments with Indian potters. Finally, since both individual- and network-level data are incomplete, we will rely on empirically-grounded, agent-based simulated models to simulate the network conditions and micro-level mechanisms under 
which the macroscopic diffusion curves observed in India and Kenya are more likely to appear. We contend that our main argument, that network reachability and local redundancy can lead as much to rapid or slow diffusion depending on the quality of the signals circulating in the network, can only be defended at the intersection of these four methods. To grasp the real mechanisms at work, qualitative studies, social network analysis, in-field experiments, and agent-based simulation are not sufficient on their own to provide an explanation. Thus, methodologically, our study makes the effort to respond to frequent, but still largely ineffective, calls for better integration between qualitative methods and quantitative social network analysis (Hollstein 2011), ethnography and agent-based simulations (Tubaro and Casilli 2010), and social network analysis and agent-based simulations (Smith and Burow 2018).

The paper is organized as follows. We first describe the Indian and Kenyan ethnographic contexts as well as the type of qualitative data we were able to collect. Second, we explain our analytical framework and the network-level measures we have used. Third, we describe the macroscopic patterns of diffusion and explain why contextual and individual-level explanations of these patterns would not be convincing. Fourth, we report on the empirical analysis of kinship networks across religious sub-groups in India and Kenya. Finally, we describe the agent-based computational models we built to recreate the observed diffusion process in silico and comment on the comparison between the empirical and simulated diffusion curves. The main contribution of the study and the generalizability of our results are discussed in a concluding section.

\section{Ethnographic case studies and empirical data}

Our first case study concerns a population of potters living in the Rajasthan (north-western India), in particular in the districts of Jodhpur and Barmer. In this area, pottery is an old and well established craft activity (Kramer 1997). Traditionally it is carried out by Muslim ("Moila") and Hindu ("Prajapat") male potters. At the beginning of the 1970s, plastic and metal objects spread throughout the region. This triggered a process of homogenization of potters' production in the Jodhpur area (for details, see Roux 2015), which is nowadays entirely centered on a specific type of jar (known as "white matkea"). These jars, made out of salty clay and tempered with sawdust and granite, in standardized shapes and sizes, are in high demand because they have the property of keeping water fresh. The diffusion process we study intersects with the change in the type of jars produced. It concerns the way in which jars are fired.

Traditionally, potters in the Jodhpur region have fired their pots in open firings. According to this technique, pots are placed over a layer of combustible material (wood in this case) and covered by pieces of broken ceramic (in order to keep the temperature high). The firing is typically 
started in the late evening and lasts for twelve hours. In other regions of India ceramic vessels are fired in an updraft kiln, a structure made of bricks coated with clay containing two superimposed chambers (the firing and heating chambers) separated by a floor. In Ahmedabad (Gujarat, SW of Rajasthan), this floor is made of metal slats lying against the wall and a central, rectangular pillar. The kiln is quite small with a heating chamber containing only fifty 30 -litre jars. In this paper, we investigate the dynamics of the diffusion of this Gujarati-type kiln among Muslim and Hindu potters in the region of Jodhpur between 1987 and 2013.

This first case study is compared with another process of innovation diffusion in pottery-making that took place in Kenya, in the municipality of Ishiara (about $200 \mathrm{~km}$ North-East of Nairobi), between 1997 and 2013. The vast majority of Kenyan potters, who are all women, live in Kiriri and Ngararigeri, two villages separated by a muddy road. Their respective centers are 5 kilometers apart. The innovation under scrutiny here is a stylistic one, in particular the transition from round- to flat-base pots. These pots are used to cook meals on modern stoves and are in high demand because of their greater stability compared to round-base pots.

Compared to Indian potters, who tend to produce 25 water jars ("white matka") a day during 8 months of the year (production usually being interrupted from July to October), Kenyan female potters produce less pots (between 6 and 10 a day), mainly during August - as farming is their main activity during the rest of the year. Whilst Indian potters sold their pots through middlemen, Kenyan potters mainly sold them personally in the same local market, which takes place every Thursday in the nearby village of Kiaritha (depending on the exact location of potters' houses, 2 to 3 kilometers separate Kiriri and Ngararigeri from Kiaritha). What is most relevant for us is that, like potters in the region of Jodhpur, the major social divide among Kenyan potters is the form of religion they practice. Although potters living in Kiriri and Ngararigeri all belong to the same Bantu ethnic group, namely Mbeere, and speak the same dialect, i.e. Kimbeere, they belong to four different Christian religious groups: Mukurino (Akorino), Apostolic, Presbyterian, and Pentecostal. Mukurino potters are the most numerous; they all live in Kiriri. In Ngararigeri, Apostolic potters are more numerous than Presbyterian and Pentecostal ones.

To study the adoption choices made by Indian and Kenyan potters with respect to the kiln and flat-base pots respectively, we primarily rely on data collected through in-depth interviews. Within the Jodhpur region, we conducted 89 interviews (in February-March 2013, 2014 and 2015) whereas, in Kenya, we interviewed 33 potters (in February-March 2014 and 2015). Interviews were conducted in the local language with the aid of a local translator. On average, interviews lasted for about 3 hours. In India, 31 out of the 89 interviews were shorter (lasting on average one hour): 
these were used to cross-validate information with potters who had been named by other potters who were interviewed in depth.

In both social contexts, interviews followed the same structure. First, potters were asked to describe their economic situation (rate, cost and organization of production and distribution system). Second, potters were asked to reconstruct their technical histories, meaning the different choices they had made during their career in terms of type of production and firing techniques. Third, potters were invited to name friends, village neighbors, and relatives who played a role in terms of proving advice and/or direct practical help in the stylistic and technical choices they made. Fourth, as ethnographers typically do (White and Johansen 2006), part of the interview was concerned with drawing the interviewed potter's family tree.

Data collection was exhaustive in Kenya. The 33 potters we interviewed were all of the active potters in Kiriri and Ngararigeri. These potters are able to respond to the demand from a market of about 7000 people living in the region of Ishiara. As to the distribution of potters' religious adherence, 14 potters were Mukurino (42\%), 12 were Apostolic (36\%), 5 were Presbyterian (15\%), and 2 were Pentecostal (6\%). Given that the Mukurinos all live in one village, i.e. Kiriri, which is also the village where diffusion was most rapid, we decided to treat Apostolic, Presbyterian and Pentecostal potters as a single subgroup (hereafter, for simplicity's sake, labelled “other-religion potters").

The Indian case is more complex because potters' communities are spread over a larger geographic area. The most reliable ethnographic sources (see Kramer 1997) suggest that 460 potter households, scattered over 47 villages, should still have been active in the Jodhpur region in 2015. For practical reasons, including the absence of a clear and specific list of these households, we could not investigate all potters in all villages, nor design a random-based sampling strategy. Instead we made a carefully planned selection of villages of varying size, religious composition, and spatial location; within each village, we then always tried to interview the very first adopter (if any), and, based on information provided by this first adopter, we approached potters who adopted after him. Over the three two-month-long periods of fieldwork, we were able to conduct interviews in 19 villages (for details, see appendix A.1). Within these 19 villages, 342 household potters were active, which represents $74 \%$ of the above mentioned estimated numbers of active potters in the Jodhpur region. On the basis of the information contained in the 89 interviews carried out in these villages, information on the date of adoption of the kiln, as well as advice and kinship ties, for 279 potters living in the Jodhpur region between 1987 and 2015 was compiled. Of these potters, 75\% are Muslim, which is in line with the large over-representation of Muslims among potters who are still 
active in the Jodhpur region (see Roux 2015).

To conclude, let us note that, in the Indian case, in-depth interviews were complemented with in-field experimental data. This concerned a specific aspect of our study, namely potters' technical skills. Although interviews contained clear indications of those persons who are perceived to be skilled potters, potters' subjective perceptions were also tested with objective measurements (for details, see Roux et al. 2018). To this end, 16 potters ( 7 being the first to have adopted within their village and 9 being later adopters) were chosen from 10 of the 19 Indian villages surveyed, and they were asked to produce both a series of their usual pots and two new shapes with increasing levels of technical difficulty. Potters were video-recorded during their production processes and their final products were submitted to a variety of measures to ascertain whether there was a correlation between the date of adoption and the potter's technical expertise This is a small, but important, complementary data source that we will use in combination with the network-level measures that we discuss in the next section.

\section{Analytical Framework and Network Measures}

At the microscopic level, the innovation decision-making process has been defined as an "information-seeking and information-processing activity" in which actors aim at the reduction of uncertainty about the advantages (or disadvantages) of the innovation at hand (Rogers 2003: 14). Innovations vary with respect to type of information, hence cognitive effort is required to perform this task of uncertainty reduction. In particular, innovations have varying levels of "complexity", "trialability", and "observability" (Rogers 2003: 15-16). The two innovations we investigate in this paper - i.e. the kiln and flat-base pots, for Indian and Kenya potters respectively - have high levels of complexity (a learning process is necessary to build and use the kiln and to manufacture the new shape), low levels of trialability (the potential of the kiln or the flat-base pots cannot be properly tested without first-hand experimentation with them), and low levels of observability (simple visual inspection is not enough to understand the internal functioning of the kiln or the way flat-base pots are made).

The complex nature of the innovations under scrutiny is the main reason why we postulate that the interpersonal relationships in which Indian and Kenya potters are embedded may be of primary importance in understanding the diffusion process of the kiln and flat-base pots across religious sub-groups. A potter may have the perception that the kiln (or the new shape) may pay-off economically; s/he may also be highly motivated to change her/his manufacturing/firing practices; and, a potter may have the technical skills successfully to make the change. However, without being in contact with other potters that can give her/him high-quality advice and concrete help about 
how to build/use the kiln (or manufacturing the new shape), the potential innovator find it hard to adopt the innovation. Being exposed to a variety of good-quality sources of information and help thus seems a necessary condition to making potters decide to switch to the new firing technique (or stylistic form). As a consequence, variation in the configuration of ties in which potters belonging to different religious sub-groups are embedded may be of crucial importance to explain differential diffusion within these groups.

As soon as this directing hypothesis is proposed, the question arises about the type of interpersonal ties that are likely to be the most effective in transmitting information and help to potters, thus making a network containing this type of ties more favorable to rapid and wide diffusion. On this point, two views continue to be at issue in the literature.

The older of the two derives from Granovetter's (1973) classical thesis about "weak" ties connections involving low investments in terms of time, affection, intimacy, and reciprocity (ibid: 1361)- according to which such ties are more likely than "strong" ties to connect distant nodes into a network (ibid:: 1364), thus conveying new information to actors. As a consequence, Granovetter speculated that "(...) whatever is to be diffused can reach a larger number of people, and traverse greater social distance (i.e., path length), when passed through weak ties rather than strong" (ibid.: 1366; emphasis added). More recent research based on formal models of network topologies has given support to this idea. Watts and Strogatz (1998: 442) show that even a small fraction of random ties (representing weak ties) introduced within a regular network (i.e. a network where each node has the same number of neighbors at distance 1), is able considerably to reduce the average distance separating each pair of nodes, and, ultimately, increase the speed and rate of diffusion of a disease (see also Watts 1999: 518-524; Watts 2004: 256-261).

It is worth noting that, although only in passing, Granovetter himself put forward a caveat on his strength-of-weak-tie thesis. He noted indeed that, whilst weak ties may facilitate the circulation of new information because people related by this type of tie are likely to participate in different social circles, it should be admitted that people related by strong ties may be more motivated to help each other in searching for and using new information (Granovetter 1973: 1371). Whether "weak" ties can a priori be considered the main driver of rapid and wide diffusion thus remains theoretically unclear.

Over the last ten years, a new view tending to reassess the privileged role of weak ties as diffusion facilitators has in fact forcefully appeared in sociology. In particular, on the one hand, it was argued that because strong ties are based on higher levels of solidarity, trust, and emotional involvement and make people interact more frequently, it is reasonable to postulate that strong ties 
in fact are likely to transmit better information than weak ties, both in terms of quantity and quality. This is the so-called channel bandwidth thesis proposed by Aral and Van Alstyne (2011: 95-100). On the other hand, it was noted that, differently from a disease, where a single contact may be sufficient to be "infected", many social behaviors require social reinforcement and learning sustained by contacts with a variety of previous adopters. Centola and Macy (2007) call these behavioral changes "complex contagions". In this case, they argue, "the transitive structure that was redundant for the spread of information now becomes an essential pathway for diffusion" (Centola and Macy 2007: 709). Within this perspective, strong, not weak, ties are regarded as the fuel of the diffusion process.

The strength-of-strong-tie view has an additional important implication. It casts doubt on the special role that an extensive literature has traditionally assigned to two types of actors in the diffusion of innovations, namely "brokers" -i.e. actors that have the capacity to connect two otherwise disconnected parts of a network (see Stovel 2012: 141)- and “opinion leaders" (Valente and Davis 1999) or "influencers" (Watts and Doods 2007) -i.e. actors with a large number of connections ("hubs" following the terminology in complex network literature, see Barabasi and Bonabeau 2003). Brokers and hubs may certainly act as injection points, transmitting new information to many diverse actors, but, if the final adoption of the new behavior requires to be exposed to a variety of previous adopters to whom the focal actor is connected through strong ties, then the information passed on by brokers and hubs may not translate into behavioral changes on a large scale because the broker's or hub's contacts may be disconnected and thus be lacking the opportunity to benefit from mutual advice and help (see Centola 2015: 1322; Centola 2018: chs. 3 and 7).

Our analytical framework builds on this debate and attempts to integrate the two theses. To this aim, we rely on an apparently minor conceptual distinction. As clearly seen by Banerjee et al. (2013), adoption decisions in fact arise at the intersection of two cognitive phenomena, i.e. "innovation awareness" and "innovation endorsement". The strength-of-weak-tie thesis, implicitly assuming that being in contact with new information (i.e. "awareness") is sufficient to adopt ("endorsement"), reduces the adoption decision to "innovation awareness". Conversely, the strength-of-strong-tie thesis, based on the correct argument that many behaviors require long decision-making processes to be endorsed, exclusively focuses on "innovation endorsement". We believe that taking seriously the distinction between innovation awareness and endorsement helps to build a more balanced analytical framework in which both weak and strong ties are seen as playing a role in the unfolding of the real-world diffusion processes of complex innovations. Weak and strong ties can in fact be seen as diffusion drivers at different stages of the process and are 
differently important for different aspects of adoption decisions.

In particular, we posit that the following working hypotheses: (bypothesis $A$ ) weak ties are likely to play a special role for "innovation awareness", namely at the beginning of a diffusion process, by making some actors aware of the existence of previously unexplored options; (bypothesis B) once the new information has reached a given social context, "brokers" and "hubs" are likely to play a special role in passing the information on to a large number of actors, thus also contributing to "innovation awareness" on a larger scale; (bypothesis $C$ ) at any stage of the process, strong ties play the crucial role of translating innovation awareness into innovation endorsement; (bypothesis D) brokers' behavior and attributes may modify the expected impact of strong ties on diffusion speed and pervasiveness.

The empirical data we collected in India and Kenya gives us a unique opportunity to investigate these hypotheses. First, with respect to hypothesis $A$, potters' narratives allow us clearly to distinguish weak from strong ties, and determine when weak ties intervened in the diffusion process of the kiln and flat-base pots. Second, with respect to bypothesis $B$ and $C$, potters' family trees make it possible to directly assess whether networks of strong ties (i.e. kinship ties, in our case) presenting at the same time many "brokers" (high reachability) ) and wide overlapping across actors' relatives (local redundancy) do favor rapid and wide diffusion - high network reachability increasing the level of innovation awareness of a large set of actors while high local redundancy helps to transform innovation awareness into innovation endorsement. Third, with respect to bypothesis $D$, since we could also collect information on the exchanges of advice among potters, we find ourselves in the favorable position of being able to compare (within each religious sub-group) the potters' positions within the network of strong ties that is supposed to sustain the circulation of advice and help with potters' positions within the observed advice networks.

In passing, let us note that, compared to previous studies of "complex contagions", where social networks were either imposed on participants by experimental design (Centola 2010) or inferred from second-order behaviors on the web (such as following a user on Twitter; Fink et al. 2016) without exactly knowing whether the underlying ties were strong or weak, we can unambiguously compare network-level properties of real-world networks of strong ties. In this sense, the empirical part of our investigation can be thought as a study of the navigability of strong ties (see White and Houseman 2003).

We will rely on the following three measures to evaluate our hypotheses. To identify potters who were likely to play a crucial role in information passing (hypothesis B), we will employ 
betweenness centrality, a simple nodal measure that quantifies the extent to which a node lies at the intersection of many paths connecting other nodes (Hanneman and Riddle 2011: 366) This statistic is often seen as a measure of how fully actors act as intermediaries (Valente 1999: 52) or "middleman brokers" (Stovel 2012: 146). Betweeness centrality can thus be used as an indicator of network reachability ${ }^{1}$. As to local redundancy (hypothesis B), to capture the extent to which potters are likely to be exposed to multiple adopters within their proximate web of family connections, we will quantify the extent to which the direct contacts of two actors, who are not directly connected but share at least one common neighbor, are also in contact. This corresponds to what is called "bridge width" within the literature on complex contagions (Centola 2008: ch. 3). More formally, the width of the bridge between two nonadjacent nodes $i$ and $j$ is given by the size of the set "of ties between, on the one hand, the common neighbors of $j$ and $i$, and, on the other side, neighbors of $j$ but not of $i$ " (Centola and Macy 2007: 713) (the description of the algorithm we have written to implement this measure is given in appendix B.1). To the best of our knowledge, our study is the first to directly measure empirically the distribution of bridge widths on real-world networks of strong ties. Finally, to study the role that brokers play in information passing (hypothesis D), we will rely on the correlation that exists between the distribution of betweenness centrality computed on the kinship and advice networks. At this point of our analysis, in order to better describe Indian and Kenya brokers, we will also use qualitative evidence and measures of potters' expertise based on the in-field experiments we mentioned in the previous section.

\section{Macroscopic patterns and weak ties}

The macroscopic explananda of our study are given in figures 1 and 2. Based on the dates of adoption declared by potters during the interviews, the two plots trace the cumulative proportion of Indian and Kenyan potters that adopted the kiln and the flat-base pots respectively over the temporal windows considered. Cumulative adoption rates are computed by aggregating (every six months) the total number of adopters across the 19 villages that we surveyed in India and the 2 villages that we exhaustively investigated in Kenya. As anticipated, we classified adoption rates by potters' religious affiliation.

Two similarities appear. First, in both social contexts, the diffusion curves exhibit a S-shape pattern characterized by a slow initial growth, followed by a quicker growth, and then again a slowly increasing tendency. This functional form is usually considered as the macroscopic signature of a

\footnotetext{
1 A synthetic measure of reachability suggested by the literature on small-world topologies referred to in the introduction would have been the average path length, i.e. the average number of ties (computed over the shortest paths) one must go through to reach two nodes (Watts 2004). However, not all the networks that we compare here are fully connected (see, in particular, figures 3 and 4), thus making the average path length a less informative measure.
} 
potentially underlying contagion-based endogenous process, where actors tend to base their decisions on previous adopters. The S-shape would emerge from the fact that, at the beginning of the process, only a few adopters exist, thus the number of possible contagions is reduced; as the number of adopters increases, more and more actors can influence other actors, thus adoption rates can accelerate; at the later stage of the process, few non-adopters remain, thus the cumulative proportion of new adopters can only marginally increase (Rossman et al. 2008: 205-208). The second common feature of Indian and Kenyan diffusion curves is that the diffusion of the innovations involved penetrated faster and wider in one of the two religious sub-groups, namely Muslims in India and Mukurinos in Kenya. In particular, by 2013, virtually all Muslim and Mukurino potters covered by our data had adopted the kiln (or the new shape) whereas only about $75 \%$ of the Hindu (in India) and other-religion (in Kenya) potters had adopted the innovation.

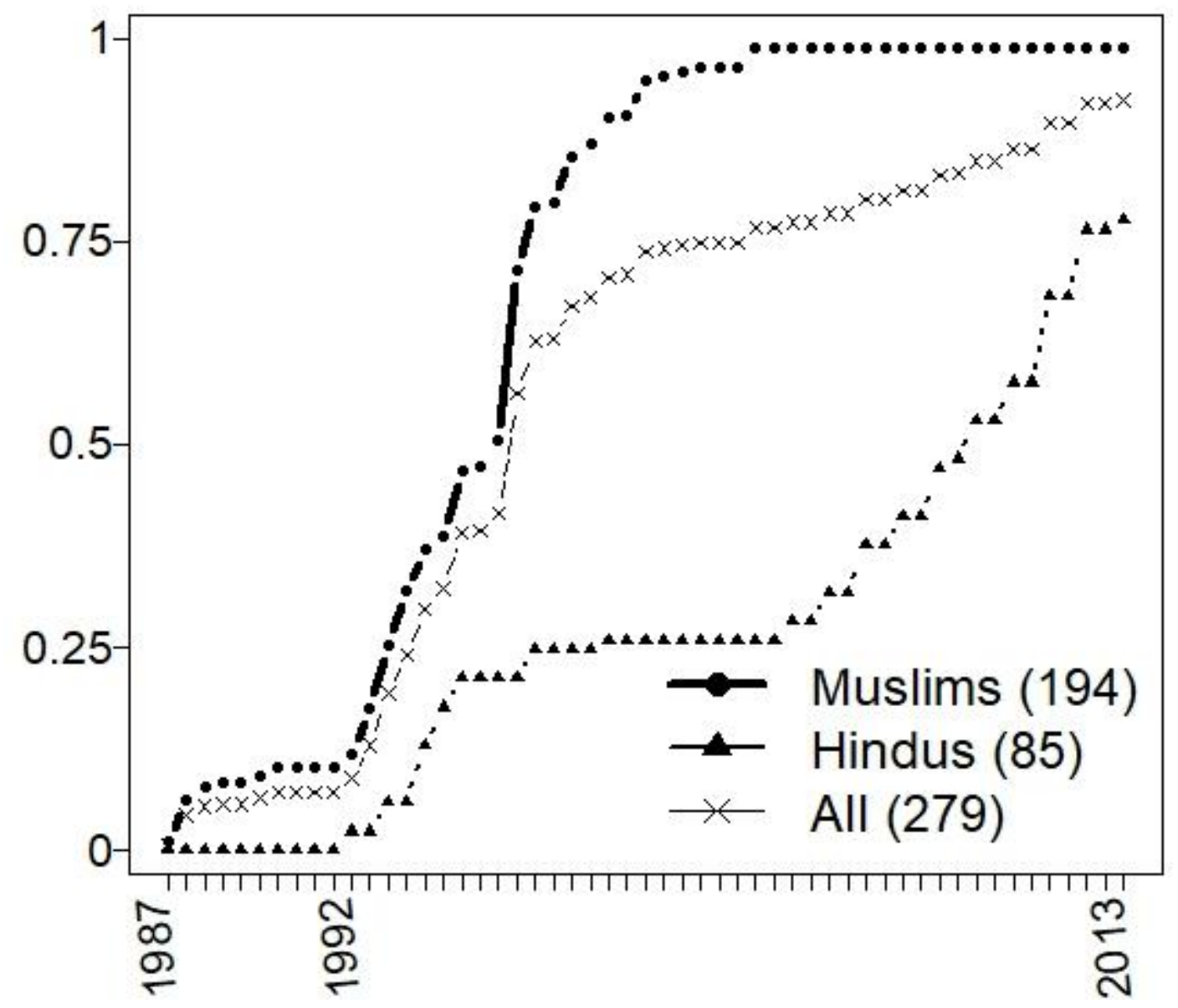

Fig. 1 Six-month evolution of the cumulative proportion of Muslim (solid circles) and Hindu (solid triangles) potters who adopted the updraft kiln in the 19 surveyed villages in the Jodhpur region between 1987 (first adoption among Muslim), or 1992 (first adoption among Hindus), and 2013. 
The richness of our qualitative data can be exploited to learn more about the beginning of the diffusion process, in particular with respect to the role that weak ties may have played at this stage. A very similar story was indeed observed in India and Kenya.

Among Indian potters, the very first adopter was a Muslim potter (BIK -throughout the article, all potters' first names are acronymized to preserve anonymity) from the village of Sar, who, in 1987, went to Ahmedabad, a city located in Gujarat (462 km from Jodhpur) for a seasonal job in a workshop managed by Hindu potters where the Gujarati updraft kiln was in use. Among Hindu potters, the diffusion started from a few, apparently disconnected, potters, namely a potter living in Jodhpur (MOD) who adopted in 1992, one potter living in Mokalsar and one in Palasni who both adopted it in 1993, and three potters (GOV, JAG, and PUK) from Pachpadra who tested the kiln for making glazed items in 1995.

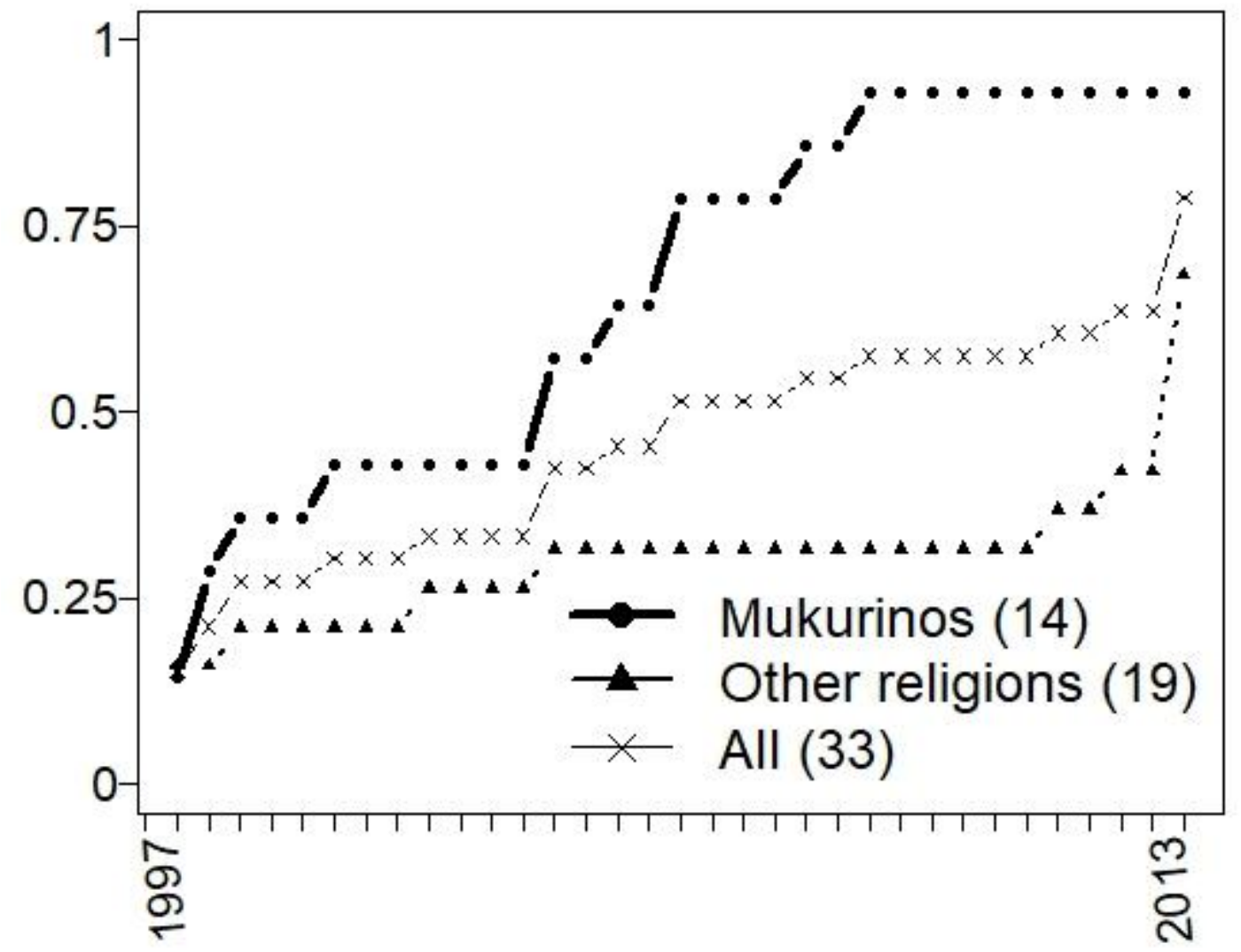

Fig. 2 Six-month evolution of the cumulative proportion of Mukurino (solid circles) and other-religion (solid triangles) potters who adopted the new form (flat based pots) in the villages of Kiriri and Ngararigeri in the Ishiara region between 1997 and 2013. 
The first Muslim adopter as well as five of the six Hindu first adopters imported the kiln in their respective villages after learning how to build and use it during seasonal jobs in ceramic workshops very far from their villages (namely, Ahmedabad, Pokhran, and Khurja). Among them, the Muslim innovator BIK and the Hindu innovator MOD illustrate the case of learning from potters who belong to another religious group. These six first adopters went to remote places because of economic problems (drought and low incomes). The Hindu first adopter living in Mokalsar is an exception. He learned how to make the kiln from a Muslim friend (HUS) living in the same village.

In Kenya, innovation also came to the surveyed villages from exogenous sources. The diffusion process began in 1997 when a business man (MUK), and his son (KIM) from the district of Meru (approximately $80 \mathrm{~km}$ from Ishiara), and belonging to a different ethnic group than the Kenyan potters, approached three potters (namely, JAT [Apostolic], JUST [Apostolic] and JAN [Mukurino]), all living in Kiriri, at a market in Kanyombara (about 5 kilometers away from Kiriri). MUK, (age 30), who had graduated in ceramics skills from the Rift Valley Institute, went to JAT's house for about two months, two or three days a week, to teach her how to make flat based pots. JUST (JAT's sister-in-law) and JAN, living very close to JAT, also participated in these learning sessions. The same year a fourth potter (MAR, Apostolic, also living in Kiriri), was approached by MUK at the source potters used for taking clay, and she also received training from him at her home for two weeks.

This qualitative evidence on first adopters thus reveals an important fact. In both social contexts under scrutiny, the diffusion process was initiated by some potters that learn about the existence and the internal functioning of the innovation through sporadic, contingent, accidental, ephemeral, and, in 10 out of 11 cases, heterophilious social contacts. In line with Granovetter's (1973) original insight, as well as a rich body of empirical research in diffusion studies (see Rogers 2003: ch. 8) showing that novelty often arrives in a given social context from exogenous injection points, weak ties were responsible in both our case studies for bringing new information to potters, thus making the beginning of the diffusion process possible. Once the innovation reached Indian and Kenya potters, however, as shown by figures 1 and 2, the diffusion process unfolded differently among Muslim and Hindu potters, in India, and, among Mukurino and other-religion potters, in Kenya.

\section{Possible confounding mechanisms}

Before we start exploring empirically our favorite explanans - which, to reiterate, concerns potential differences in the kinship connections across religious sub-groups - we believe that it is 
important to firstly discuss possible confounding mechanisms so that our case for a network-level explanation is better justified.

\section{Common Exposure}

A first possible alternative explanation for the patterns of figures 1 and 2 is that potters among whom the diffusion was faster correspond to potters that were exposed to a most effective common source of influence. The fact that diffusion curves follow a sigmoidal trend is actually insufficient per se to prove the existence of a genuine network-based contagion process. Famous empirical cases exist where S-shape diffusion curves initially interpreted as deriving from differences in network exposure were subsequently discovered to have been generated by advertising campaigns to which sub-groups were differently exposed (Van den Bulte and Lilien 2010). As noted by Young (2009: 1901, 1919), functional forms describing aggregate diffusion curves should be complemented by "contextual details" and "micro-level data" to exclude the effects of exposure to common sources of influence.

In this respect, potters' qualitative narratives contain precious information. The Kenyan case is simple. After the initial contact between the middleman "MUK" (and his son) with the four first adopters (three Apostolic and one Mukurino potters, let us recall), whom he taught how to make round-based pots, there is simply no trace of any common external intervention to which Mukurino potters could have been exposed more intensely than other-religion potters.

The Indian case is a more telling one. Among Muslim potters, in some villages, common learning sessions took place. In one case, this was organized by the government, in Banar, in 1985. This intervention was described by Muslim potters as having no effect on them because they did not understand how to build the kiln. More often, however, common learning sessions were endogenous. In particular, one (or more) potters went to another potter's house to teach him how to build/use the kiln. Potters described this phenomenon in 6 out of 14 villages where Muslim potters were active - namely, Salawas (in 1987), Sangasni (in 1990), Banjara (in 1990), Rudakali (in 1993), Ramasani (in 1995), and Banar (in 1995) - involving respectively 5, 2, 39, 5, 12, and 14 potters. In all these villages, however, even when all the potters attended the public "class" (as in Banjara and Banar), the final adoption took, according to the potters' own accounts, from 6 months to 6 years depending on the potter, suggesting that flows of dyadic interactions, following the common learning session, were in fact essential in order to get further advice and help, and finally in deciding to adopt the kiln.

Among Hindu potters, "public" learning sessions only took the form of external, top-down 
interventions. In particular, the Rajasthan "Small Industries Craft Organisation" from Jaipur targeted Pachapdra potters because of their reputation as good potters. The goal of a first intervention in 1995 was to introduce the Hindu potters to the glazing technique which required the firing of small items in the kiln. A "workshop" was organized at the house of one of the two most skilful potters in the village (GOV). Fifteen potters attended the demonstration. They found the glazing procedure very complex and nobody expected themselves to be adopting the kiln. The "Small Industries Craft Organisation" made a second attempt in 1997, but again the initiative was unsuccessful. In 1998 a third attempt was made by this organization, which, this time, presented a different type of kiln and proposed to underwrite its cost of production. The kiln was small and was designed to fire glazed pottery. About twenty potters attended the workshop but only four of them decided to build a kiln. They all abandoned it after two to four years because they had problems with making and selling the glazed items. Thus, similarly to the Muslim villages, the Hindu potters' exposure to common sources of informational advice cannot be considered to be a driver of the diffusion process. Public shared learning sessions have without a doubt increased Muslim and Hindu potters' innovation awareness but, within both sub-groups, they were clearly insufficient in the end to push potters to endorse and permanently use the kiln.

\section{Market conditions and cost-benefit ratios}

From a broad rational choice perspective (see Boudon 2003, 2014; Ermakoff 2017; Opp 1999), a second possible confounding mechanism would be a systematic variation across religious sub-groups in the perceptions of the costs and benefits of moving to the kiln (or the new pot shape). The argument would be that Indian Muslim potters and Kenyan Mukurino potters would have on average more favorable incentives than Indian Hindu and Kenyan other-religion potters respectively to adopt the innovation. Although we do not have full information on socio-economic differences across the 279 (and 33) Indian (Kenyan) potters for whom we were able to trace adoption decisions, potters' narratives and contextual knowledge allows us confidently to exclude the presence of an amount of unobserved individual-level heterogeneity in order that the by-group patterns of figures 1 and 2 would simply reflect this heterogeneity.

In this respect, three factors must be considered. First, both in India and Kenya, religious sub-groups were exposed to the same market conditions and selling system. As we have explained earlier, from the 1980s market demand in India was focused on a specific type of jar (the so-called "white matka"), which created a competitive situation between Muslim and Hindu potters who were now required to produce the same type of items. No difference exists in the selling system. Indian potters sold their pots through middlemen who told Muslim and Hindu potters the number 
of pots it would be reasonable to send to the market. Similarly, in Kenya, the Mukurino and the other-religion potters are all exposed to an increasing demand for flat-based pots, which buyers regard as both esthetically more attractive and more adapted to modern stoves. As to the sales system, all potters sell their pots personally by going weekly to the same local market (in a village named Kiaritha, as close to Kiriri as it is to Ngararigeri).

Secondly, both in India and Kenya, potters from the different religious sub-groups appear to clearly see the in-principle advantages of the two innovations at hand. In India, virtually all early adopters among the interviewed potters, no matter whether Muslim or Hindu, mention one, or more, of the following technical factors as the reason(s) that pushed them to switch to the kiln: a/ compared to open firing, the kiln requires less time to prepare the firing, essentially because sawdust can be used as its fuel instead of wood; b/ it requires less fuel; c/ it reduces direct production costs because wood factories will usually supply potters with sawdust for free whereas access to free wood depends on village location and local rules; $\mathrm{d} /$ it requires less firing time (varying between 2 and 5 hours depending on the amount of pots fired); e/ it makes the firing schedule less dependent on weather conditions because pots within the kiln are protected against wind and rain ${ }^{2}$. Similarly, in Kenya, both Mukurino and other-religion potters clearly know the economic advantages of flat-based pots. On the local market where they sell their pots, and can monitor each other on a weekly basis, flat-base pots are sold at twice the price of traditional round-base pots (namely, in 2014, 200 Ksh versus 100 Ksh).

Thirdly, both in India and Kenya, there is no trace of systematic variation across religious sub-groups as to the affordability of the initial economic investment to adopt the innovation. The cost of building the kiln is low. Potters agreed on our estimation of about 85 Euros, which corresponds to the prices of the iron bars and the bricks, and the number of days during which the potter cannot produce pots. Given the monthly income of the surveyed potters, which, no matter whether they are Muslim or Hindu, varies between 100 and 200 Euros, and the fact that one third of the cost of the kiln in fact is an opportunity cost, not an out-of-pocket cost, the initial economic investment required to move to the kiln is largely affordable. Indeed, among potters for whom we have detailed interviews, only one Muslim late adopter in Sangasni and a few Hindu potters in Pachpadra, mentioned the cost of the kiln as one of the factors that they consider when making up their mind about whether or not to adopt it. In Kenya, the situation is even clearer. Moving to flat-base pots does not require any initial economic investment, and the manufacturing time of the new shape is virtually the same as for round-base pots (about half an hour to make the shape and

2 For an "objective" comparison of firing techniques, which is in fact in line with our potters' own perceptions, see Gosselain (1992) and Livingstone Smith (2001). 
between 2 and 3 hours for the pot to dry before it is fired).

\section{Motivation}

The question of the potters' motivations to innovate represents a last potential factor that merits brief discussion. Here the argument would be that, even if it is accepted that Indian Muslim potters and Kenyan Mukurino potters do not have a systematically more positive incentive structure than Indian Hindu and Kenyan other-religion potters respectively, the former potters were in fact systematically more motivated to innovate. Again, we believe that historical and contextual knowledge, and potters' narratives suggest that this supposedly on-average difference is unlikely to exist.

In the Indian social context, making and selling pottery is the main revenue source for all potters. Both Muslim and Hindu potters have basic living standards. Maintaining, or improving, one's income, which the kiln would allow, is a valuable goal, one that is necessary in order to get better food, more education, and rare consumption goods (such as a refrigerator, TV or scooter); to build concrete houses; and, above all, to accumulate resources for marriage dowries. It is thus unclear why Muslim potters should be on average more motivated by better gains than Hindu potters. In fact two factors suggest that, paradoxically, the contrary may be true. First, before the increase in demand for white matka, Hindu potters sold their pots within a stable selling system, where they gave pots to local landowners in exchange for cereals (a system known as the jajmani system). When the jajmani system disappeared, Hindu potters who decided to continue making pottery had to enter a market-oriented system where they competed with Muslim potters, which clearly required a propensity to innovate and adapt to changing conditions. Demographics would also suggest that Hindu potters may have a stronger desire to succeed. The youngest Hindu potters we could interview do indeed tend to stay at school longer than the Muslims, more education being an individual-level attribute correlating with early adoption (see Rogers 2003: 288).

In the Kenyan social context, the situation is slightly more complex. Kenyan potters' living standards depend on pottery but also on farming, thus one may suspect that Mukurino potters are more motivated to adopt the new shape because they need to compensate for lower incomes from farming. In fact, the potters' own narratives suggest that farming opportunities are similar across Mukurino and other-religion potters, with the areas of their farmed plots varying in size between 1 and 3 acres in both Kiriri and Ngararigeri. Having access to a piped water supply - which may decrease the dependency on pottery because farming becomes more efficient, thus more productive - does not seem to be a disincentive either: among potters who benefitted from piped water, $72 \%$ made the transition to the new shape, with no significant differences across the two 
religious groups (chi-squared, Fisher, as well as two- and one-side Mann-Whitney tests lead to the same conclusion). Individual-level attributes, such as age and education, which are known correlates of a higher propensity to innovate, are widely overlapping across the two religious groups. Finally, it is important to note that both the Mukurino and other-religion potters both require $30.000 \mathrm{Ksh}$ per year to be members of a regional water project. Given that one flat pot can be sold for $200 \mathrm{Ksh}$, this is not a negligible amount of money and it is likely to motivate both the Mukurino and other-religion potters to profit more from their work by manufacturing the new shape.

Thus, in the absence of evidence suggesting that the intergroup differences in the rate of diffusion of the kiln, in India, and flat-based pots, in Kenya, may have arisen because of systematic variations between groups in terms of their exposure to common sources of influence, market conditions, incentive structures and/or the motivation to innovate, we now turn our attention to a possible network-level explanation. In the next section, we will investigate in particular the network of family ties in which Indian Muslim and Hindu potters, on the one hand, and Kenyan Mukurino and other-religion potters on the other hand, were embedded, and try to determine if any relevant difference exist as to the capacity of those strong ties to direct high-quality information and help about the two innovations.

\section{Macroscopic patterns and strong ties}

Coding potters' narratives and coupling them with their family trees (for an example of these data, and their limitations, see appendices A.1 and B.2 respectively), we obtained the kinship networks for Muslim potters, Hindu potters, and, on the other hand, Mukurino and other-religion potters shown in figures 3, 4, and 5 respectively. Kinship networks among Muslim and Hindu potters are plotted separately because marriage rules in this social context are such that no kinship ties can exist between Muslim and Hindu potters (for details, see appendix A.2). By contrast, since family ties can exist between Mukurino and other-religion potters - this is the case of 74 out of 186 kinship links (see figure 5's black dotted lines) - we plotted the Kenyan kinship network as a whole in a single graph. Potters presented in figures 3-5 are exactly those for whom we plotted the adoption choices in figures 1 and 2, hence it is legitimate to think in terms of co-occurrence between network-level features and macroscopic patterns of diffusion.

Let us start with the kinship networks within the Indian social context. With respect to our chosen indicator of network reachability (i.e. between centrality) and local redundancy (i.e. bridge 
width) significant differences appear between Muslim and Hindu potters ${ }^{3}$.

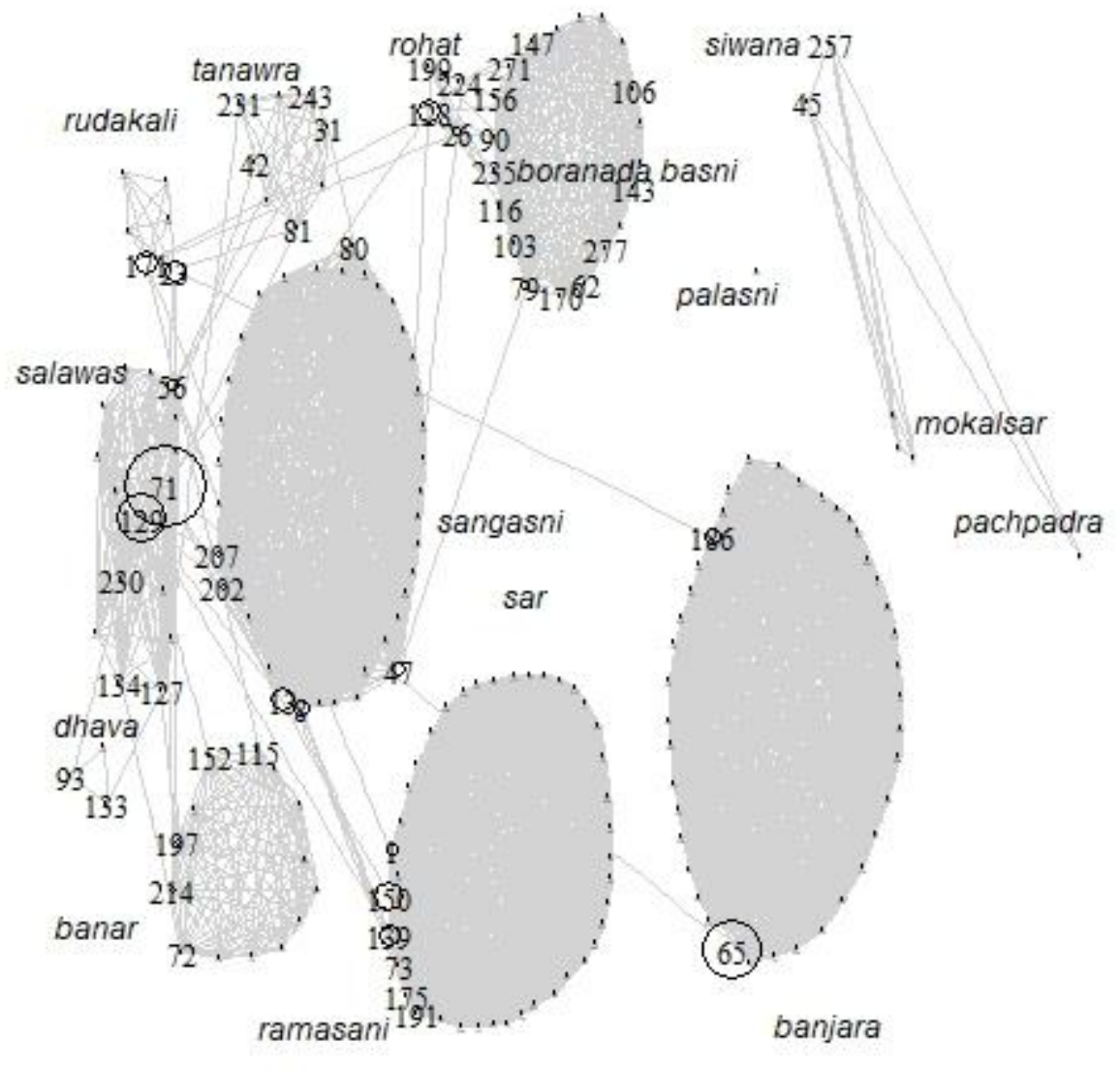

Fig. 3 Kinship ties among Muslim potters (194 nodes; 2703 links; density=0.14). When a tie is drawn between ego and alter, this means that a family connection exist between them. The nodes' size is proportional to the nodes' (normalized) betweenness centrality. The node's ID is displayed only when the node's betweenness centrality is higher than zero.

As to the distribution of potters lying at the intersection of many family ties (i.e. family brokers), the proportion of potters with a betweenness centrality higher than zero - those for whom the ID is displayed in figures 3 and 4 - is larger among Muslim potters (27\% [53 in absolute number] versus $22 \%$ [19 in absolute number]). Muslim family brokers also have a greater capacity for kinship brokerage. Among them, five potters have a betweenness centrality higher than 10 (and ten

3 Unless differently specified, all network visualizations and statistics were produced using the igraph $\mathrm{R}$ package (version 1.0.1). 
others have a betweenness centrality between 0.04 and 10) whereas this is the case of only one Hindu potter, all other Hindu potters having a value lower than 0.04. The stronger kinship brokerage capacity of Muslim potters translates into numerous family connections across virtually all Muslim villages. This contrasts with the family ties among Hindu potters, where inter-village kinship connections essentially come from one potter, i.e. GOV (ID 27), from Pachpadra, belonging to the "Eniya" clan within the Purubiya caste, who lies at the intersection of family ties with relatives in Siwana, Mokalsar and Dara. This fragmentation arises from the endogamous nature of castes and complex marriage conventions between clans within a given caste -which explains, for instance, the absence of "family brokers" between Hindu-Purubiya and Hindu-Banda who live side by side in Pachpadra ${ }^{4}$.

If we now move on to quantify the amount of local redundancy in terms of bridge widths -i.e. the size of the set of family ties relating direct relatives of two potters that are not directly connected but share at least one common relative (see section "Analytical framework and Network Measures", and appendix b.1)-, noticeable differences also appear between Muslim and Hindu potters. We found 2106 pairs of not-directly-connected potters involving a family bridge containing at least one family tie as against 728 non-zero-width bridges among Hindu potters. Although, relative to network size, this corresponds to a larger fraction of non-zero-width bridges among Hindu potters - namely, about $11 \%$ of all potential not-directly-connected pairs of nodes compared to $6 \%$ for Muslim potters (see appendix B.3 for the procedure we followed to compute this fraction) -, the average bridge width among Muslim potters is 16.37 whereas this value is only 8.3 for Hindu family bridges. In addition, the distribution of family bridge width is more dispersed within the Muslim kinship network (SD: 13.33 versus 4.58). Very large family bridges - for instance, bridges made of more than 30 ties - involve 438 dyads (i.e. 21\% of the total observed bridges) among Muslim potters, whereas the maximum value observed among Hindu potters is 16 (only for 1 out of 728 existing bridges). Thus, although proportional to the size of the network, the Hindu kinship network presents a slightly larger fraction of family bridges containing at least one family tie, Muslim family bridges are, on average, larger and more dispersed towards very large widths.

Thus, the religious sub-group where the diffusion of the kiln was more rapid and wider, i.e. Muslim potters, corresponds well to the sub-group where family ties are more reachable and locally redundant, which may have facilitated a faster circulation of information through family brokers as well as a wider exposure to opportunities for receiving concrete help within a tightly overlapping

\footnotetext{
4 It should be noted in passing that a few previous empirical studies (see, for instance, Rao et al. 1980) found that social fragmentation (in terms of sub-castes and clans) among Indian Hindu farmers slowed down diffusion of agricultural innovations within this community.
} 
local web of relatives.

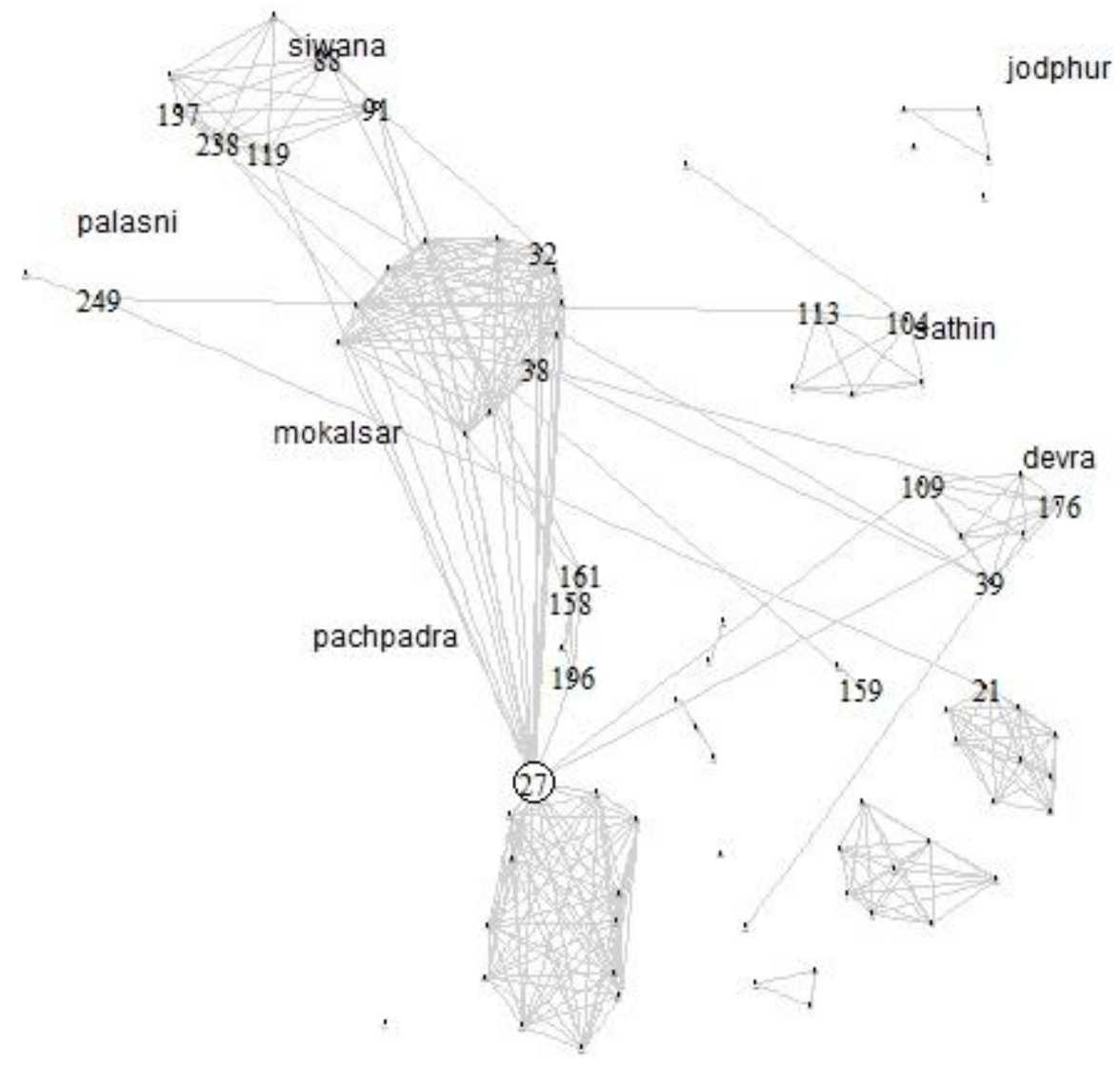

Fig. 4 Kinship ties among Hindu potters ( 85 nodes; 301 links; density=0.08). When a tie is drawn between ego and alter, this means that a family connection exists between them. The nodes' size is proportional to the nodes' (normalized) betweenness centrality. The node's ID is shown only when the node's betweenness centrality is higher than zero.

The Kenyan case suggests however that one should be prudent about considering high reachability and local redundancy as necessary and sufficient conditions to trigger rapid diffusion. The comparison of family ties among Mukurino and other-religion potters indeed suggests that the underlying mechanisms may be more complex. 


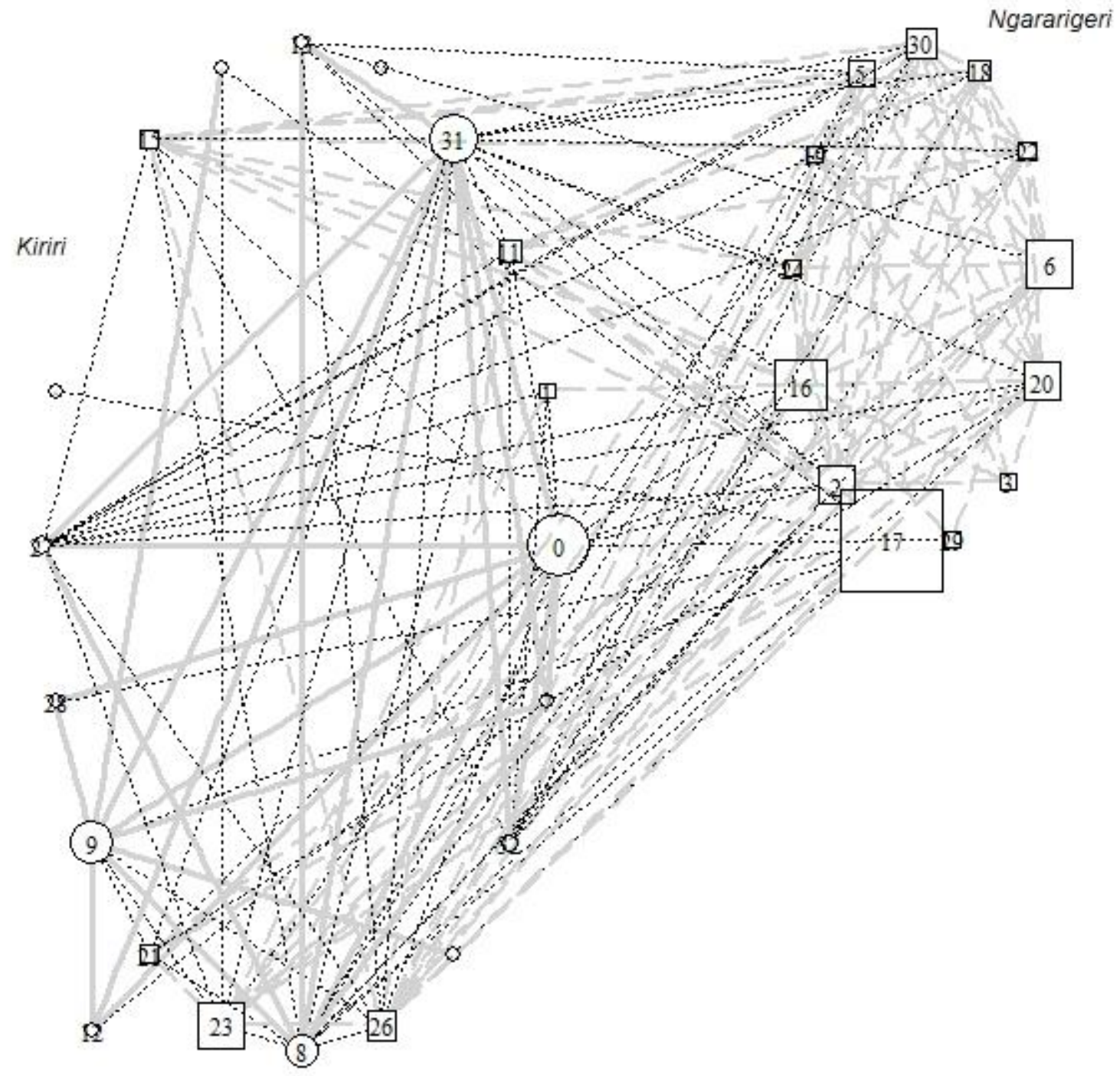

Fig. 5 Kinship ties among Mukurino potters (14) (circles) and other-religion potters (19) (squares). 186 links are present, distributed in the following way: Mukurino-Mukurino ties (gray solid lines) $=24$; Other-other-religion ties (gray, long dashed lines) $=88$; Mukurino-other-religion ties (black dotted lines) $=76$. The nodes' size is proportional to the nodes' (normalized) betweenness centrality. The node's ID is displayed only when the node's betweenness centrality is higher than zero.

As for family brokers, visual inspection of figure 5 suggests that potters lying at the intersection of many kinship chains are more present among other-religion potters (squared nodes). The distribution of betweenness centrality confirms this impression showing that, among the 29 (out of 33) potters with positive betweenness centrality (i.e. those for whom the ID is displayed) -, $65 \%$ of them are other-religion potters.

As to the widths of the bridges - which, to reiterate, are measured here as the size of the set 
of family ties relating direct relatives of two potters that are not directly connected but share at least one common relative (see section "Analytical framework and Network Measures", and appendix b.1) - other-religion potters (rather than Mukurino potters) exhibit the most locally redundant family structure. Among the other-religion potters, we found 156 pairs of potters related by a bridge of length at least equal to 1 - which corresponds to $61 \%$ of all potential pairs of not-directly-connected nodes (see appendix B.3 for the procedure we followed to compute this fraction). The average width of these bridges is $7.4(\mathrm{SD}=3.6)$. The percentage of non-zero-width bridges falls to $44 \%$ among Mukurino potters (70 in absolute number), the average width being 2.9 $(\mathrm{SD}=1.6)$. The structure of the distributions of bridge widths among Mukurino and other-religion potters also shows that, whereas narrow bridges make up the vast majority of bridges among the former (70\% of non-zero-width bridges have a width equal to 1,2 or 3), among the latter more than $50 \%$ of non-zero-width bridges have a width higher than 7 (which is the maximum width observed among Mukurino potters).

Thus, unlike the Indian case, the religious sub-group where the diffusion of the kiln was more rapid and wider, i.e. the Mukurino potters, does not correspond to the sub-group where family ties are more reachable and locally redundant. In the Kenyan social context, network features that the literature that we have reviewed in the section "Analytical framework and Network Measures", regards as diffusion facilitators -i.e. brokers, who are supposed to make new information travel faster through distant parts of the network, and tightly overlapping local neighborhoods, which are supposed to increase actors' opportunities of being exposed to multiple sources of information and help - cannot be invoked alone to explain faster and wider diffusion among Mukurino potters.

\section{Brokers' behavior}

According to our hypothesis D (see section “Analytical framework and Network Measures”,), it is possible that family brokers, despite their structural position, may have specific behaviors that modify the expected impact of network-level features on the pace of diffusion.

To investigate this hypothesis, we extracted from potters' narratives potters who were named as being responsible for making a given potter aware of the kiln (or of the new shape) and/or giving concrete advice/help about it, thus reconstructing the advice networks for Muslim potters, Hindu potters, and, on the other hand, Mukurino and other-religion potters. Potters that are present in these advice networks (that we omit because of space constraints but are available upon request) correspond to those that were also present in the family networks shown in figures 3-5, thus ensuring that exactly the same set of actors for whom we plotted the adoption choices in 
figures 1 and 2 can be compared with respect to her/his family and advice ties (for advice data limitations, see appendix B.4). Then, after checking that kinship ties can be reasonably considered as a major channel of circulation of advice and help within the religious sub-groups under scrutiny (see appendix B.5), we investigated more specifically the correlation that exists between family brokers and "information" brokers, that is potters who lie at the intersection of many advice chains.

We found that among Indian Muslim potters where the diffusion of the kiln was especially rapid, the Pearson correlation between the distributions of the betweenness centrality previously computed for the kinship and advice networks is 0.66 . When we require an even more demanding test, considering the exact rank of each potter within the two distributions, the Spearman rank correlation among Muslims is still relatively high (0.45). Among Indian Hindu potters, for whom the diffusion of the kiln was far slower, the values of these two correlation coefficients fall to 0.17 and 0.20 respectively. The Kenyan social contexts present similar results. Among Mukurino potters where the diffusion of flat-based pots was faster, the Pearson correlation between the distributions of the betweenness centrality previously computed for the kinship and advice networks equals 0.60. When one considers the exact rank of each potter within the two distributions, the Spearman rank correlation among the Mukurinos is still relatively high (0.42). Among other-religion potters, where diffusion was much more limited, these two values fall to 0.18 and 0.26 respectively.

Thus, in both social contexts, the religious sub-group where the diffusion of the innovations was slower and more limited -i.e. Indian Hindu potters and Kenyan other-religion potters- corresponds to the sub-group where potters who can be identified as family brokers tend not to be information brokers. Considering that Kenyan other-religion potters were in fact characterized by a network of strong ties that was highly reachable and locally redundant, this fact suggests that these network-level properties, which are usually considered as a diffusion facilitator, did not produce the expected macroscopic effect because the potters who were in the structural position of making information and help move through the network did not perform this role in full.

There are identifiable reasons why family brokers' involvement in the circulation of advice and help may have played such a crucial role as modifiers of network-level properties. Potters with the highest value of betweenness centrality on the family networks tend to be early-adopters in their respective villages. Among Indian Muslim potters, this is the case of CHA (ID 71) (adoption in 1987), IQB (ID 129) (adoption in 1987), ASK (ID 155) (adoption in 1990), HAN (ID 8) (adoption in 1990), BIK (ID 127) (adoption in 1987); among Indian Hindu potters, this is the case of GOV (ID 27) and JAG (ID 21) (both making a first trial of the kiln in 1995); among Kenyan 
other-religion potters, this is the case of JAT (ID=11), JUST (ID=15), and MAR (ID=21) (all of them adopted in 1997); among Kenyan Mukurino potters, this is the case of AGN [ID=0] and VID [ID=31] (both adopting in 1997). Being early-adopters in turn seems to be associated with a specific attribute, i.e. the potter's technical abilities. As we have previously said, we were able to carry out field experiments in India so we could directly measure potters' abilities. We discovered that the potters that we have just mentioned indeed had high levels of technical expertise as well as cognitive abilities to recognize the advantages of the kiln (see Roux et al. 2018). Although for Kenya potters we could not carry out the same experimental measures, we know that the three above-mentioned first adopters among other-religion potters had received high-quality training from an expert learning source and the two above-mentioned first adopters among the Mukurino potters were unanimously recognized within the Kenyan potter community as "very good potters".

This correlation between potters' network centrality, early adoption, and strong technical skills may explain why the degree of real involvement of family brokers in the circulation of advice and help is consequential. When those potters do not fully play the role of information brokers that they could in principle perform because of their structural position, then their lack of involvement lowers the quality of the signal about the innovation and the help that can concretely circulate within the network. Under this condition, high network reachability and local redundancy may not suffice to trigger rapid and wide diffusion.

The Kenyan social context contains the clearest empirical traces of this phenomenon. Within the religious sub-group presenting the highest reachable and most locally redundant family networks, but also unexpectedly the slowest diffusion, i.e. other-religion potters, JAT (ID=11), JUST (ID=15), and MAR (ID=21) were the first to adopt the flat based pots after learning how to make them from a good learning source (i.e. MUK, the skilled businessman). However, despite having numerous family connections with many other-religion potters JAT, JUST, and MAR are in the second and third quartile of the distribution of the family betweenness centrality), they did not play any special role in spreading the innovation among other-religion potters -none of these three other-religion potters have positive betweenness centrality on the advice network. The only other-religion potter with positive betweenness centrality on the advice networks (i.e. ONA $[\mathrm{ID}=23])$ had learned how to make flat based pots from MAD [ID=17], a potter who did not learn how to make flat based pots from a qualified source but on her own, namely by trying to imitate the pots she saw in the market ${ }^{5}$. This contrasts with the Kenyan sub-group presenting the lowest reachable and less locally redundant family networks, but also the fastest diffusion, i.e. Mukurino

5 During the interview, MAD acknowledged that the approach she followed to manufacture the new shape makes her pots more fragile. 
potters, where the five potters with the highest betweenness centrality on the advice networks all directly learned from one of the three very early adopters (who, as we have repeatedly noted, were all taught by the best source of advice, i.e. the businessman MUK).

To sum up, comparing the strong ties of our four religious sub-groups clearly suggests that network features such as high reachability and local redundancy may not be sufficient to sustain rapid and wide diffusion. The macroscopic effect of these network properties seems modified by the specific behavior of the actors occupying central network positions. Indian Muslim potters present positive values on all the required dimensions. Their network of strong ties is highly reachable and locally densely connected; in addition, family brokers are high-quality expert potters who are fully involved in making advice and help circulate within the network. Rapid and wide diffusion (of the kiln) was observed. Hindu Muslim potters present negative values on all the required factors. Their network of strong ties is fragmented and weakly connected locally; in addition, the rare family brokers who also are high-quality expert potters are only partially involved in the circulation of advice and help. Slow and limited diffusion (of the kiln) was observed. Kenyan Mukurino potters present negative values on the two network ingredients and a positive value of the individual-level element. Their network of strong ties is weakly searchable and locally redundant but the high-level expert potters occupying network central positions made advice and help circulate the network. Fast and wide diffusion (of the flat based pots) was observed. Kenyan other-religion potters present positive values on the two network ingredients and a negative value on the individual-level factor. Their network of strong ties is highly reachable and locally redundant but high-quality, early-adopter brokers were not involved in the person-to-person transmission of the new method, thus limiting the advisory opportunities practically available among other-religion potters. Slow and limited diffusion (of the new shape) was observed.

\section{Empirical Diffusion curves from the bottom-up}

The evidence we have produced so far to explain why the observed rates of diffusion differ across religious sub-groups is intrinsically correlational. We have shown that network features of strong ties, namely reachability and local redundancy, co-occur with rapid (slow) diffusion in the Indian social context but, contrary to expectations, not in the Kenyan one. To explain why this may have been the case we have investigated a second set of co-occurrences, that between being a broker, being an early-adopter, being a expert potter, and, at the same time, being involved in the circulation of high-quality advice and help. By putting these two pieces of information alongside each other, we finally proposed that high reachability and local redundancy can in fact lead to both rapid and slow diffusion depending on the quality of the signal circulating within the network as a 
consequence of the specific behaviors and attributes of the main network brokers.

This explanation seems plausible. However, a clear micro-to-macro gap remains in our analysis. First, the proposed explanation postulates the existence of a contagion process. But what is the specific mechanism that may have driven this process? Second, the proposed explanation combines network features (i.e. reachability and local redundancy) with nodal behaviors (brokers' involvement in the circulation of information). But what is the relative weight of the postulated mechanisms? Our network data are not fine-grained enough to answer these questions empirically. As discussed in appendices B.2 and B.4, our family networks are robust and detailed but they only describe structural constraints. By contrast, advice networks that may help to describe the specific contagion mechanisms at work, given these constraints, only contain limited traces of the flows of advice and help underlying the real-world diffusion process.

For these reasons, we now design computer simulations in order to complement our empirical network-oriented investigation with formal theoretical deductions based on an explicit theoretical model of the contagion process that may have generated the observed diffusion curves we plotted in figures 1 and 2. Within a computer simulation one has total control of the mechanisms at work. In our case, we will be in position to check whether the network features of the family of strong ties within the different religious sub-groups are in fact sufficient to generate the observed by-group differences -which would run against our proposed explanation where nodal behaviors are considered as modifiers of network effects. We will also be in the position of manipulating the type of influence mechanism at work, in particular playing on the difference between "single" (i.e. one contact suffices) and "complex contagions" (i.e. contacts with several previous adopters are needed) -again, should be find that the first type of influence is sufficient to reproduce the observed diffusion curves, this would run against our proposed explanation where potters are supposed to learn through repeated interactions within their local family neighborhood. Finally, we will be in position to assess whether "complex contagion" mechanisms are necessary to generate not only fast diffusion but also slow diffusion - if this should not this be the case, we would have difficulty in defending an explanation according to which complex contagions would reinforce doubt when highly-expert brokers are not fully involved within the circulation of information, thus ultimately leading to limited diffusion.

To produce these arguments about which mechanisms are sufficient to generate the observed diffusion curves, we will more specifically rely on agent-based computational models, a computer simulation technique which is especially flexible in designing alternative micro- and network-level mechanisms (for a general overview of the method, see Manzo 2014a, and references therein; for agent-based models for empirical research, see Bruch and Atwell 2015). It is worth 
stressing that, compared to existing agent-based models of innovation diffusion (see, for instance, Deffuant et al. 2005; Delre et al. 2010; and, for an overview, Watts and Gilbert 2014), including those specifically built to study the role of "complex contagion" (Centola 2015), our model will be empirically calibrated with respect to both individual and network-level information. Although this does not support in any way the claim that our simulation results will constitute an empirical proof of our proposed explanation, the empirically-grounded character of the simulations increases the plausibility of the theoretical arguments in terms of generative sufficiency that we will present in favor of, or against, this explanation.

\section{The structure of the simulated models}

Each of the 194, 85, 14, and 19 artificial agents respectively representing Indian Muslim, Indian-Hindu, Kenya-Mukurino, and Kenya-other-religion potters is characterized by: 1/ a geographical location, i.e. the village where the real-world potter lives; 2/ a set of individual-level attributes - namely a name, an age, a level of technical ability, and a religion -, whose values derive from our in-depth interviews and/or field experiments (for expertise); 3/ one relational attribute, i.e. the (betweenness) centrality computed on the empirically reconstructed kinship networks that we studied in the previous section. Each agent also has the two following endogenous, individual-level attributes (meaning that their value is generated during the simulation): a/ the adoption decision; b/ the time of the decision (both expressed in semesters). These are the agent-level simulation outcomes they will be compared with, by using the values empirically observed in order to assess the capacity of the model to generate the observed diffusion curves displayed in figures 1 and 2.

Within such an empirically-grounded artificial population, taking inspiration from potters' narratives which all describe episodes of information transmission during face-to-face encounters, we have designed a process where, at each iteration, some of the agents who have adopted make some potential adopters aware of the to-be-adopted trait. At the beginning of the simulation, the only artificial adopters that are present correspond to the Indian and Kenyan potters whom we identified empirically as first adopters, namely those who brought the innovation to the surveyed villages from outside through weak ties (see section "Macroscopic patterns and weak ties"). Further adoptions then flow from these very early innovators through the (empirical) networks of strong ties - a dynamic structure on which pioneering simulation models of the diffusion of innovation were built (see Hägerstrand 1971: 50-51). Given this starting point, one then has to take three modeling decisions to make an artificial diffusion process unfold: $1 /$ the choice of the adopter who is more likely to transmit the information; 2 / the criterion the selected adopter follows to choose a potential adopter; and, 3 / how the potential adopter who was reached by the information makes his 
final decision about whether to adopt or not. Within our analytical framework, 2/ and $3 /$ respectively correspond to the distinction between a potter's innovation awareness and endorsement (see section “Analytical Framework and Network Measures”).

(Adopters selection) As to the selection of the source of information, we consider four criteria. First, since our network evidence suggested that being at the intersection of several family ties can lead to also being a central actor in the act of providing advice and help to potential adopters, betweenness centrality computed over the observed kinship ties seems a reasonable selection criterion. Second, since we know that central actors tend also to be early adopters (on this regularity, see Valente 1999: ch. 3; more generally, on the positive effect of being a central actor, see Rivera et al. 2010: 103-105), who in turn seem to be high-level experts (see Roux et al. 2018), potters' skills may be another reasonable candidate for the selection of the agents from which information and help flow at each iteration. Third, our interviews suggest that, in some potter households, innovation was delayed because fathers disagreed with their sons about the advantages of the kiln ${ }^{6}$. Thus we cannot exclude the possibility that age also played a role in the activation of those who spread information and help. Since our data do not allow us to quantify the correlation between these three attributes, we consider network centrality, expertise, and age as alternative selection criteria for the adopters. In each case we postulate a continuous probabilistic rule in such a way that the higher the centrality, the expertise, or the age of the artificial agent, the higher the probability that this agent will be selected as the source of information for the current iteration. Random selection of the adopter who is going to make another potter aware of the innovation constitutes a fourth criterion, which we use as baseline modeling option.

(Potential Adopters selection) Once an adopter has been selected, in line with our network-oriented analytical framework, a natural criterion that can be followed, to determine what agent the adopter is more likely to make aware of the innovation, is relational distance. According to this, the selected adopter will interact with an artificial agent who has not adopted yet as a (linear) inverse function of the number of ties (i.e. the path length) separating them - the path length being computed from the empirically observed kinship networks. Thus, in this model version, the shorter the path length between the selected adopter and a potential adopter, the higher the probability the former makes the latter aware of the innovation. This rule is in line with empirical evidence suggesting that, as Rivera et al. (2010: 101) put it, "shorter network distances are correlated with increased tendencies toward connections", in particular when actors who are close in a network

\footnotetext{
6 In particular, in the Indian social context, it was reported that in Sar (1 case), Sangasni (5 cases), and Bipalsur (1 case), some sons had had to push their fathers to adopt the kiln; in Tanawra (1 case), the son of one potter was only able to adopt the kiln once he had left his father's household and established his own pottery business. This suggests that the authority on the final decisions about whether or not to change technology may reflect the age pyramid.
} 
"are close through numerous independent intermediaries" -which, as we have seen in the previous section, is, although to a different extent, the case of many of our Indian and Kenyan potters. In a second variant of the model we follow an alternative criterion, namely physical distance among potters. This corresponds to a classical hypothesis in diffusion studies in geography (see Hägestraand 1971) and archeology (Clarke 1968; Davis 1983), where spatial propinquity is often considered the by-default mechanism explaining faster diffusion and clusters of cultural/technical practices. The reason for this is that being close in space may make encounters and communication more likely (for an overview on this point, see Rivera et al. 2010: 105-107), a fact that, through digital data, has now been confirmed at a very large scale (Lambiotte et al. 2008; Krings et al. 2009). Thus, although, within our analytical framework, physical distance is not a central theoretical element, it would be an important controlling factor for this aspect. That is why, in this version of the model, the adopter will transmit the information about the innovation to a potential adoptee as a (linear) inverse function of the physical distance that separates his own village from the village of the potential adopter, so that the physically closer the selected adopter is to the potential adoptee, the higher the probability that the former makes the latter aware of the innovation.

(Potential Adopters' decision) The last crucial modeling choice concerns the decision mechanism the potter who is now aware of the innovation (hence, a potential adoptee) follows to make his mind about whether to adopt it or not. The micro-level mechanism we designed focuses on the contagion, network-related part of the decision process that may have driven the diffusion of the kiln and the new shape among Indian and Kenyan potters. In particular, our modeling choices are intended to give our simulation the capacity to compare the macroscopic consequences of "simple" versus "complex" contagions, the former implying that "contact with a single source is sufficient for the target to become informed or infected" whereas the latter requires "an individual to have contact with two or more sources of activation" (Centola and Macy 2007: 706, 707). We also aim at showing that "complex contagions" themselves can in fact be represented in different ways ${ }^{7}$.

As a consequence, we designed the following four decision mechanisms. According to the first, a potential adopter follows the simplest decision rule: as soon as s/he gets in contact with an adopter, s/he in turn deterministically, without any delay, adopts. This mechanism -which characterized Hägerstrand's (1971: 50-51) ante litteram agent-based model of the diffusion of

\footnotetext{
7 Let us clarify that, as we model the diffusion of technological innovation with economic consequences, one may want to explicitly represent a cost-benefit analysis at the agent-level (for an example of this, see, for instance, Young 2006, 2011). As we have explained in section 3, however, there are good empirical reasons to think that, in both social contexts, there is no by-group systematic difference with respect to the evaluations of the payoffs of the innovations under scrutiny. For this reason, we treat the kiln's cost-benefit ratio as constant across the two communities, and omit it from the micro-level decision mechanisms we postulate.
} 
innovations - represents the most extreme form of "simple contagion": one dyadic contact suffices to be "infected". Innovation awareness and endorsement coincide. The second mechanism instead posits a first possible way complex contagions may affect potters' adoption decisions. In particular, the potential adopter is supposed to consider her/his direct kinship contacts, weight each of them by their kinship centrality (which expresses the idea that ego may place a higher value on the decisions of his most central contacts), and be (logistically) sensitive to the proportion of these direct relatives who have adopted. This mechanism follows DiMaggio and Garip's (2012: 107-108) suggestion about how modeling social learning processes within networks, and it is reminiscent of Valente's (1999: 70) original idea of "network threshold". In the third version of the model, the width of the bridges, the network measure Centola and Macy (2007: 710) associate with the concept of "complex contagions", directly enters into the agent's adoption decision. In particular, we postulate that the potential adopter takes into account the width of the bridge connecting his direct neighborhood to the direct neighborhood of the adopter who selected him, and, the wider the bridge, the higher the probability he adopts (again a logistic function is used to map bridge width into the final decision). Finally, the fourth decision mechanism goes beyond this pure structural interpretation of the concept of "complex contagions", and postulates the following decision rule: the larger the proportion of adopters that are present on the bridge connecting the direct neighborhood of the potential adopter and that of the adopter who approached her/him, the higher the probability that the potential adopter adopts (again we rely on a logistic function to determine the agent's final probability of adopting).

\section{The analysis of the simulated models}

Our ultimate aim is to establish which combination of structural conditions and micro-level decision mechanisms is sufficient to generate the most realistic diffusion curves when the postulated nuts and bolts are repeatedly executed across tens and tens of dyadic encounters between adopters and potential adopters. To this end, we will simulate the following eight combinations of mechanisms, sequentially, from the simplest to the most complex ones.

We first simulate the model when spatial propinquity is used by adopters to reach potential adopters and simple contagion is supposed to drive potential adopters' decisions (models 1-4 in figures 6-9). Then, leaving the decision mechanism unchanged, we introduce relational distances as the rule to select potential adopters at each iteration (models 5-8 in figures 6-9). Given that the decision mechanism here is so minimal (being selected by an adopter means adopting in turn), these two model variants allow us to test the extent to which spatial proximity alone or, alternatively, network reachability alone, are sufficient to generate the observed diffusion curves -(as potential 
adopters adopt as soon as they are "touched" by a previous adopter, local redundancy by construction cannot play any role in these model variants. As to spatial proximity, we expect that it should matter more within the Kenyan social context, given that the two villages we investigated are only 5 kilometers apart (compared to the Muslim or Hindu villages that respectively are, on average, separated by about 63 and $108 \mathrm{Km})$.

In a third step, to assess what complex contagions add over single contagions, we simulate the life of our artificial society introducing, once at a time, the three mechanisms we postulated to relate the potential adopter's decision to her/his exposure to relatives having already adopted. Each of the three forms of complex contagions are simulated, first, under the assumption that potential adopters are chosen according to their physical distance from previous adopters (models 9-12, 17-20, and 25-28, in figures 6-9), and, then, using the relational distance criterion (models 13-16, 21-24, and 29-32, in figures 6-9).

As to the two forms of complex contagion mechanisms where the potential adopter directly takes into account the width of the bridge or the proportion of adopters on that bridge, it is worth stressing the originality of our approach. Insofar as the observed kinship networks are plugged into the simulation, we are in the best position to assess the extent to which structural differences in terms of local redundancy between religious sub-groups do matter for the explanation of macroscopic diffusion patterns. Compared to existing simulation-based studies of complex contagions (see in particular Centola 2015 and Fink et al. 2016), where the analysis of complex contagions is performed indirectly through the number of adopters accumulating into the focal node's immediate neighborhood, in our model real-world differences between the networks of the two communities directly enter the argument of the agents' decision function, thus allowing us to assess the impact of network topologies containing more or less local redundancy on the macroscopic patterns of diffusion in a very direct way.

\section{Simulation results}

The surface plots in figures 6-9 summarize the result of this analysis for the Indian-Muslim, Indian-Hindu, Kenyan-Mukurino, and Kenyan-other-religion potters respectively. The plots have a common structure. On the x-axis, we put the thirty-two model variants we have simulated. This results from the eight model variants we have just described (i.e. four types of micro-level adoption decision mechanisms, by two possible ways adopters reach potential adoptees) each of which is simulated under the four possible criteria we described to select the adopters who, at each iteration, are at the origin of a given act of information and help transmission (namely, always in the same 
order, age-based, expertise-based, kinship-centrality-based, and random selection) $)^{8}$. On the z-axis, for each model combination, we report the Euclidian distance between the simulated and empirical diffusion curves. In particular, the plotted values derive from the comparison of the empirical diffusion curve (displayed in figures 1-2) and the average simulated curve obtained for each model variant when this model variant is replicated 100 times -the darker the surface, the poorer the fit. In fact we also take a second fit measure into account, namely the average (absolute) difference between the simulated and the empirical dates at which a given potter adopted. We omitted the plots for lack of space but we will consider it to justify the choice of our preferred model. On the $\mathrm{y}$-axis, we report the interaction rate (IR) under which each model variant is simulated. This parameter determines the number of adopter/potential adopter pairs that are (randomly and asynchronously) sampled at each iteration (for details, see appendix B.6) ${ }^{9}$.

\section{Simple contagion model variants}

A first set of results that should be discussed concern model variants where the simulated diffusion process is driven by geographic (models 1 to 4 ) or, alternatively, relational (models 5 to 8 ) proximity, and potters adopt deterministically after a simple contact with a single adopter (simple contagions). Under these conditions, no matter which religious sub-group is considered, in all of our four artificial populations the average distance between the empirical and the simulated curves remains relatively, and homogeneously, high. In particular, on average, the Euclidian distance is about 3 for models 1 to $4(\mathrm{SD}=0.48)$, and 3.12 for models 5 to $8(\mathrm{SD}=0.31$ ) among simulated Indian Muslim potters (figure 6); about 5 for models 1 to $4(\mathrm{SD}=0.31$ ), and 3.30 for models 5 to 8 $(\mathrm{SD}=0.90)$, among simulated Indian Hindu potters (figure 7); about 2 for models 1 to 4 ( $\mathrm{SD}=0.53$ ), as well as for models 5 to 8 ( $\mathrm{SD}=0.63$ ), among simulated Kenyan Mukurino potters (figure 8); and, about 4 for models 1 to $4(\mathrm{SD}=0.57)$ and about 3 for models 5 to $8(\mathrm{SD}=0.65)$, among simulated Kenyan Other-religion potters (figure 9) - in all sub-cases the low value of the standard deviation is a good reflection of the stability of this result across different modeling options with respect to the selection of adopters and interaction rates.

\footnotetext{
8 This is a form of robustness check in the sense that, in the absence of empirical information to adjudicate between different modeling choices, we assess the extent to which the core mechanisms of our models are stable across different adopter selection criteria (for a short introduction to robustness analysis, see Railsback and Grimm, 2011:302-6).

9 Again, since we do not have precise and extensive empirical information on how often potters exchange information and help about the kiln, we decided to run the simulation under different interaction rates. This is a form of sensitivity analysis in the sense that we assess the extent to which the core mechanisms of our models are sensitive to the value of a numerical parameter for which empirical setup is not possible (for a short introduction to sensitivity analysis, see Railsback and Grimm, 2011:293-297).
} 


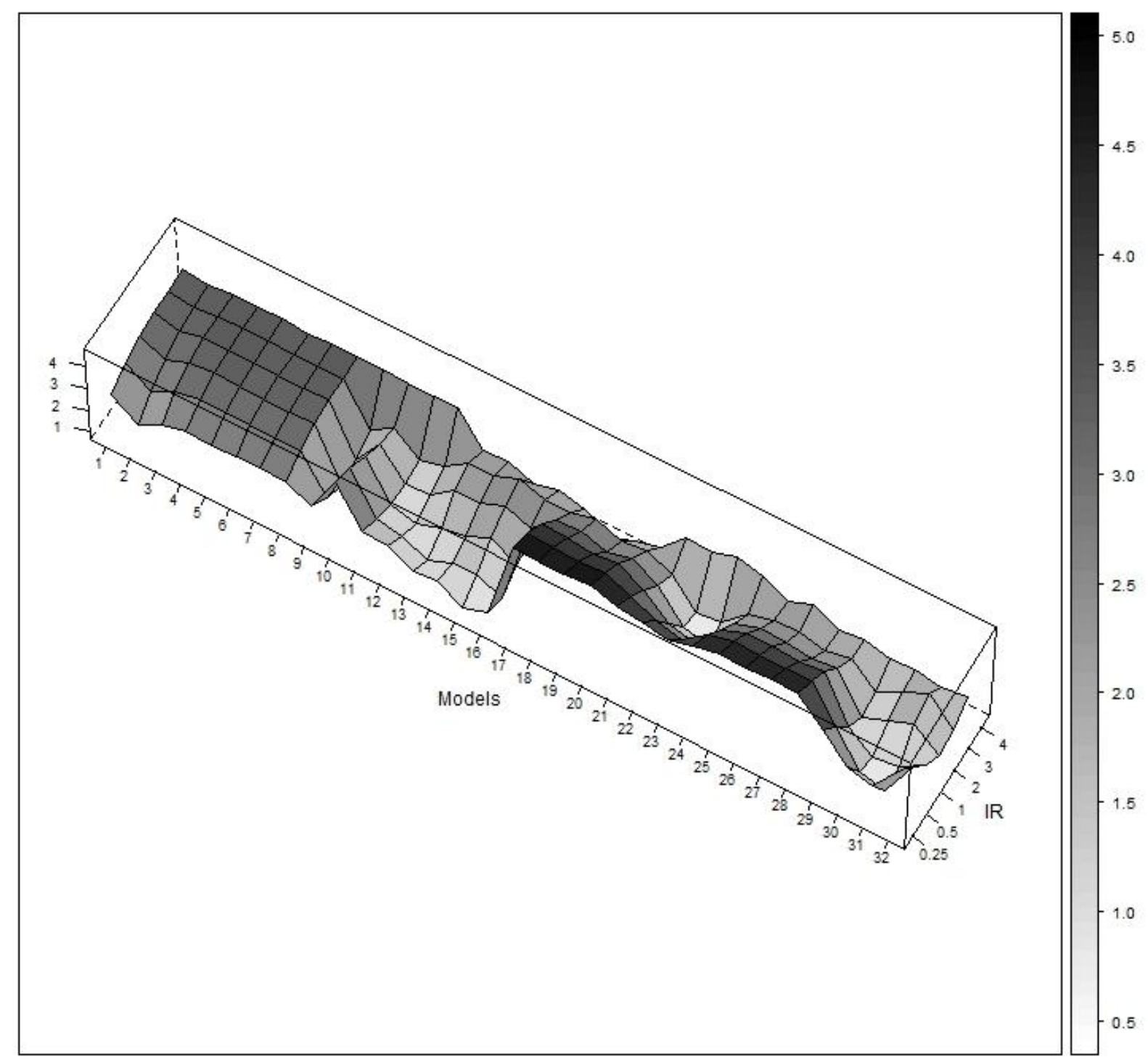

Fig. 6 Euclidean distance (z-axis) between the cumulative adoptions curve observed among Muslim potters and the averaged (across 100 replications) simulated cumulative adoption curve generated by 32 different agent-based models (x-axis), under different interaction rates (y-axis). Models 1-4=propinquity + deterministic single contagion; models $5-8=$ geodesic distance + deterministic single contagion; models $9-12=$ propinquity + complex contagion $1(\%$ adopters among direct neighbors); models 13-16= geodesic distance + complex contagion 1 ; models 17-20= propinquity + complex contagion 2 (bridge width); models $21-24=$ geodesic distance + complex contagion 2; models $25-28=$ propinquity + complex contagion 3 ( $\%$ adopters on the bridge); model 29-32 = geodesic distance + complex contagion 3 . In each group of models, always in the same order, the first, second, third, and fourth model corresponds to age/expertise/centrality/random as criteria to select the adopters from which information about the kiln flow at each iteration.

Surface plots for Indian Hindu and Kenyan Mukurino potters require a special comment. Their careful inspection indeed shows that some local minima appear in connection with models 5-8, where network distance, plus deterministic simple contagions, are the main drivers of the simulated diffusion process. As these two religious sub-groups are those with the lowest network 
reachability, this simulated behavior would suggest that low reachability of the Hindu and Mukurino kinship networks contributes alone to the observed diffusion process more than high reachability of strong ties within Indian Muslim and Kenyan Other-religion potters. In fact, when one inspects the corresponding simulated diffusion curves, it appears that network closeness alone generates more (less) adoptions, and at a much faster (slower) pace, than is empirically observed, which suggests that other mechanisms that slow down (accelerate) the diffusion process must be at work among Indian Hindu and Kenyan Mukurino potters ${ }^{10}$.

Thus, spatial proximity or closeness of the family network alone, combined with a minimalist micro-level decision mechanism based on simple contagion, are not able to generate realistic diffusion dynamics at the aggregate level in any of the religious sub-groups under scrutiny.

\section{Complex contagions model variants}

A second set of results that should be discussed concerns model variants where agents' adoption decisions are (probabilistically) contingent on the decisions of other agents to whom they are in contact through their (real-world) family connections, when, in other words, complex contagions enter the decision function of our artificial agents. Under this condition, light gray, or white, areas clearly appear in the surface plot showing that these model variants are able to generate simulated diffusion curves that are much closer to the empirical ones compared to models based on simple contagions. This holds for all four religious sub-groups under scrutiny, even though the specific model variants reaching the best fit present some differences.

In particular, within the artificial population representing Indian Muslim potters (figure 6), the most noticeable fit improvement is observed for models 29-32, where artificial previous adopters target potential adopters through network closeness (as usually, computed over the real-world kinship network), and artificial potters decide to adopt as a probabilistic (logistic) function of the proportion of adopters existing on the bridge relating the adopter's direct relatives to the potential adopter's. Among these four model variants, we find the model variant with the best fit (namely, model 30, for which the Euclidian distance from the observed empirical curves is 0.69). This model has four desirable features: $1 /$ it generates simulated curves that closely match the S-shaped pattern of the observed diffusion curves; $2 /$ it generates the lowest across-replication variability, thus containing the lowest uncertainty in the simulation dynamics; 3 / it generates simulated diffusion curves that fully contain the empirical diffusion curves over the largest interval (19 versus 13 semesters); and, it generates the lowest difference between the adoption dates of real

10 The $192 * 4$ (averaged) simulated curves generated by our models cannot be shown for lack of space. Needless to say, they are available upon request. From time to time, we will discursively rely on these simulated diffusion curves to justify the selection of our preferred models. 
potters and the time where our artificial potters adopt during the simulation (in particular, the model variant 30 makes mistakes of about 3.5 years in the individual-level adoption timing) ${ }^{11}$.

A very similar result holds for the artificial population representing Indian Hindu potters (figure 7). Although a larger set of model variants led to a considerable fit improvement (in particular, for low to medium interaction rates), which translates into a smoother fit surface, the lowest difference between the simulated and empirical curves is observed for model variants 30 (with interaction rate equals 1) and 31 (with interaction rate equals 0.25 ), for which the Euclidian distance respectively is 0.34 and 0.41 . Despite a slightly worse average fit, we favor model variant 31 because $1 /$ it generates simulated diffusion curves containing far less across-replication variability; $2 /$ it generates simulated diffusion curves capturing on a larger temporal window the complex alternation of steady states and rapid increases characterizing the diffusion curve empirically observed among Hindus; and, 3/it generates a lower difference between the adoption dates of real potters and the time when our artificial potters adopt during the simulation (model variant 31 makes mistakes of about 9 years on average in the individual-level adoption timing). Insofar as this model variant is based on network proximity for the transmission of information and on bridge-based complex contagions for the final adoption decision, essentially the same model that best reproduced the observed diffusion curve for the Muslim community also generated the most realistic aggregate diffusion dynamics among Hindu potters ${ }^{12}$.

Within the artificial population representing Kenyan Mukurino potters (figure 8), bridge-based complex contagions are also required to generate the most realistic simulated diffusion curves. The model that at the same time produces the lowest Euclidean distance (i.e. 0.38), the lowest average difference between potter-level empirical and simulated adoption times (i.e. about 6 years), the averaged simulated curve that best reproduces the S-shape pattern characterizing the empirical diffusion curves, and the lowest across-replication variability, namely

11 Let us stress that this model variant is a very good fit with the observed diffusion curves under an interaction rate of 1. This means that the simulation postulates that, over the entire temporal window under observation, i.e. 26 years, about 9360 interactions (i.e. about one a day) included discussions about the kiln. Given the size of the Muslim family network, the geographic area involved, as well as the family habits of the Muslim community, where family members meet very frequently, this seems a realistic flow of kiln-related interactions (compared to the interaction rate of other model variants showing similar aggregate curve fitness).

12 The differences actually concern the interaction rate - which turned out to be lower for the simulated Hindu population - and the selection criterion for the adopter(s) from whom information flows at each iteration - which turned out to be centrality, rather than expertise. As to the interaction rate, given the smaller size of the Hindu family network, the geographical distances between spouses and their original village, as well as the family habits of the Hindu community, which, as we have noted, tend to limit meeting opportunities, a lower flux of kiln-related interactions namely, 2340 (i.e. about 90 interaction a year) - seems a realistic difference compared to the simulated Muslim population. As to the selection criterion for the source of influence, it is interesting that expertise works more poorly than centrality in the simulation for Hindu potters. We noted in section 3 that it is likely that the best potters were not necessarily the most deeply involved in the diffusion process. 
model variant 24 , indeed postulates that information transmission is driven by geographic proximity and that potential adopter's decisions are an increasing (logistic) function of the proportion of family contacts who have already adopted the new form, these contacts being those who lie on the bridge that connect the adopter's and potential adopters' direct relatives.

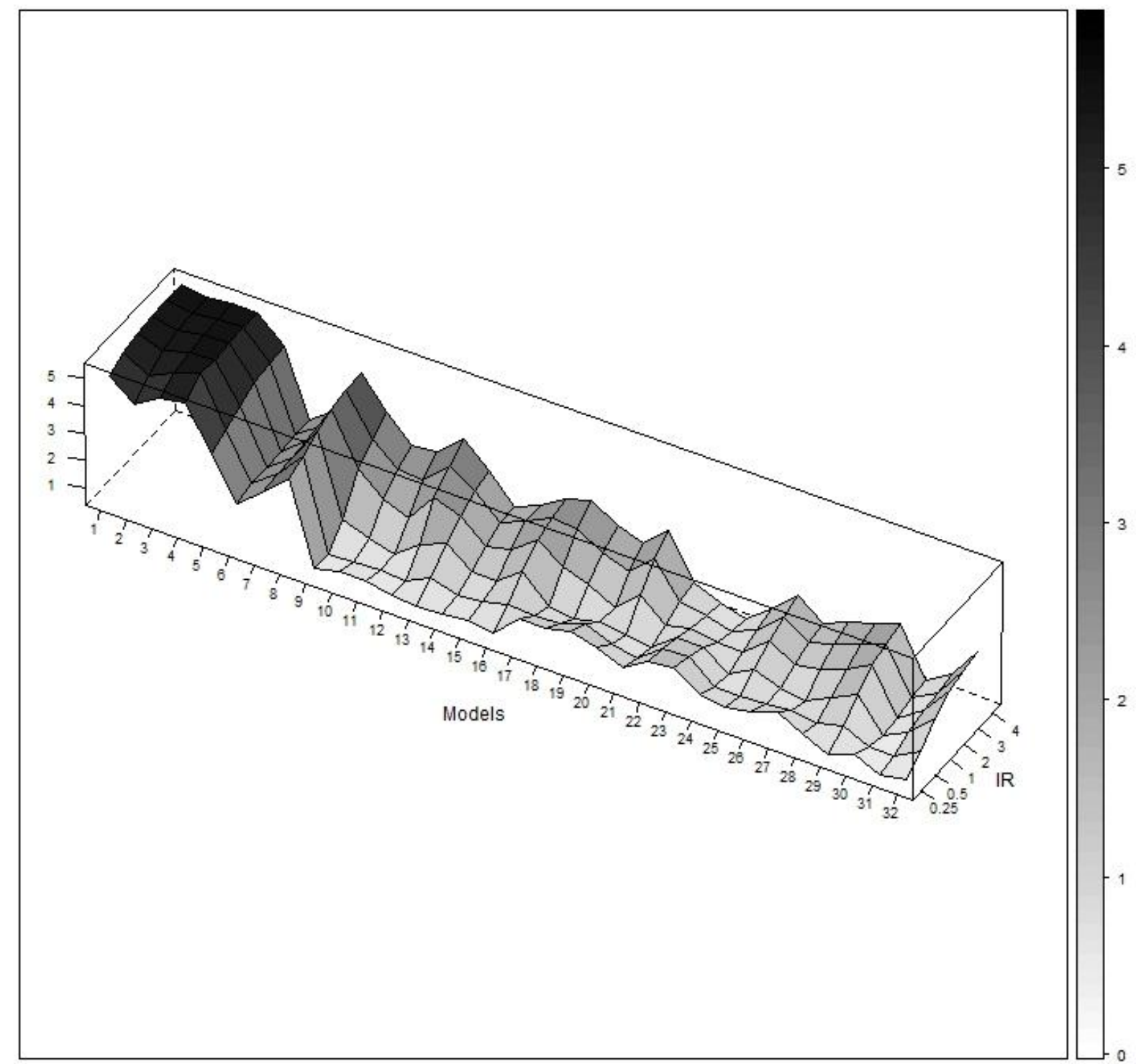

Fig. 7 Euclidean distance (z-axis) between the cumulative adoptions curve observed among Hindu potters and the averaged (across 100 replications) simulated cumulative adoption curve generated by 32 different agent-based models (x-axis), under different interaction rates (y-axis). (for more details, see figure's 6 legend). 


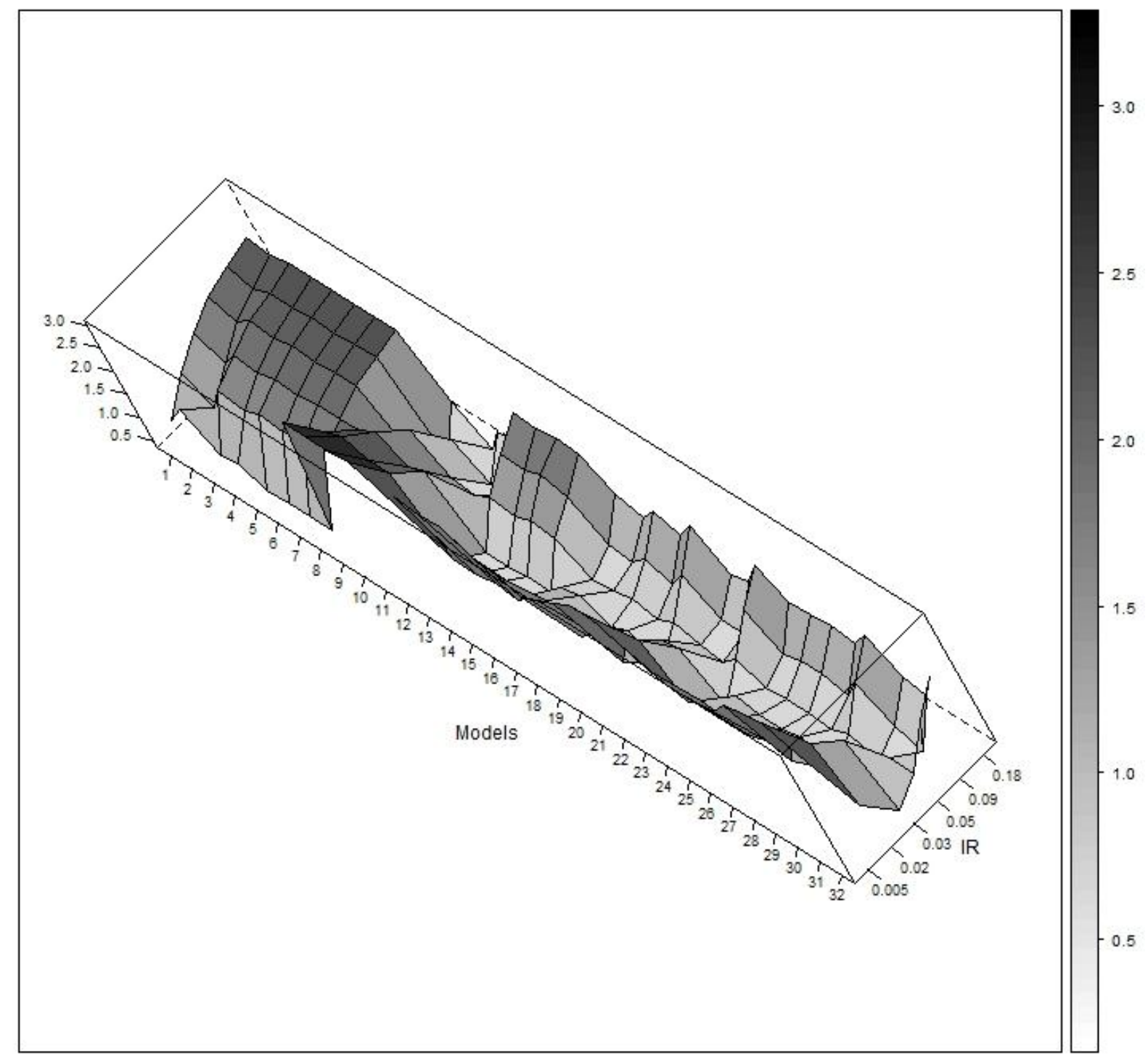

Fig. 8 Euclidean distance (z-axis) between the cumulative adoptions curve observed among (Kenya) Mukurino potters and the averaged (across 100 replications) simulated cumulative adoption curve generated by 32 different agent-based models (x-axis), under different interaction rates (y-axis). (for more details, see figure's 6 legend)

Simulations performed for Kenyan other-religion potters lead to a similar conclusion (figure 9). In particular, model variant 18 generates an Euclidean distance equal to 0.37 and, at the same time, compared to modeling options that generated a similar fit, also produces the simulated diffusion curves that, with the lowest amount of across-replication variation, best follow the complex combination of small increases and steady-states characterizing the empirical adoption curves among other-religion potters (the average difference between potter-level empirical and simulated adoption times, i.e. about 10 years, also corresponds to the lowest observed value). This model postulates that, similarly to Mukurino potters, pairs of adopters and potential adopters are 
iteratively selected (here at a pace of 1 pair of adopters/potential adopters every six months) on the basis of their geographic proximity and that, once a potential adopter is selected, then, differently from Mukurino potters, the probability the potter adopts the new shape is an increasing (logistic) function of only the width of the bridge that connects the adopters and potential adopters' direct family neighborhoods.

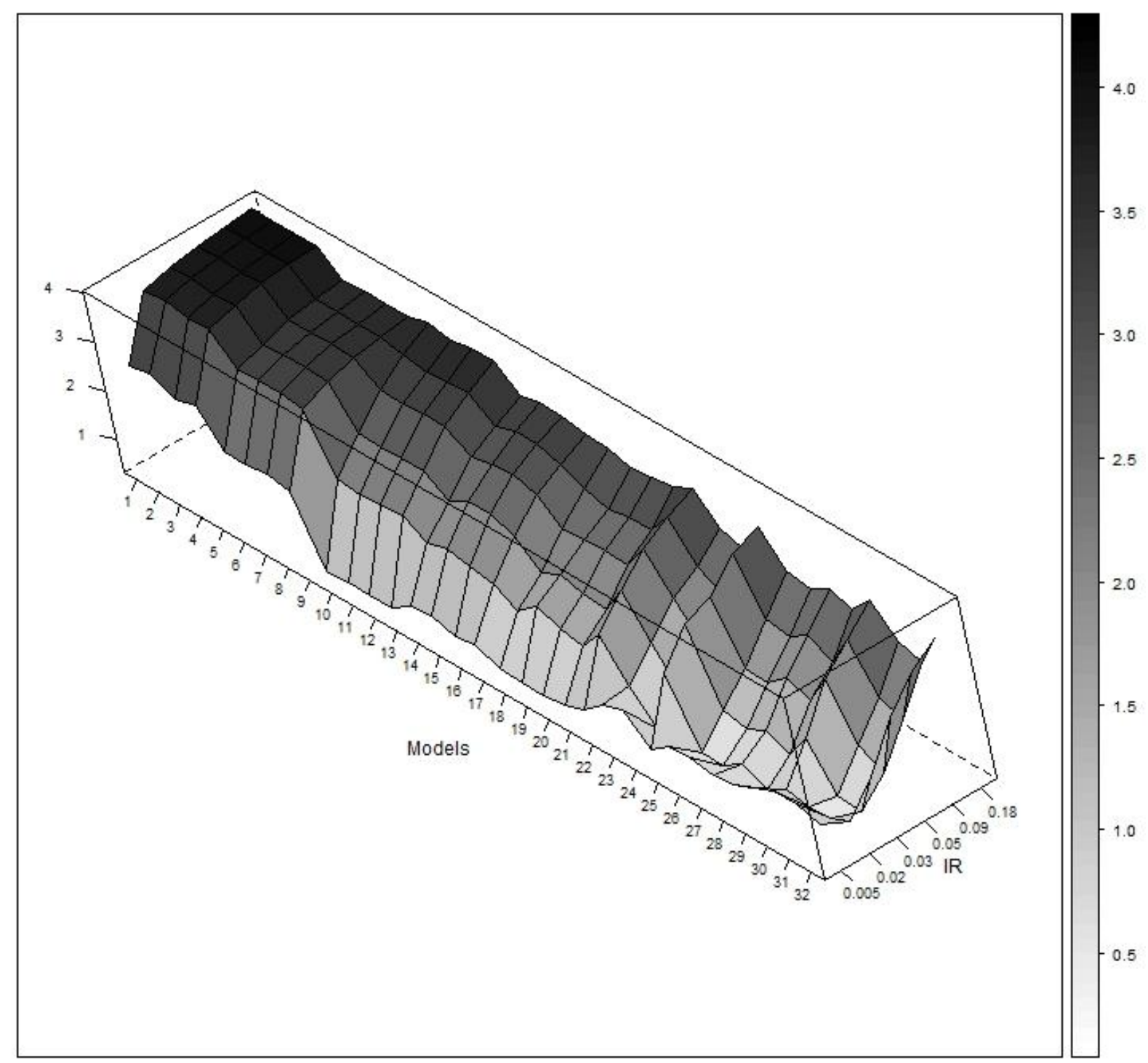

Fig. 9 Euclidean distance (z-axis) between the cumulative adoptions curve observed among (Kenya) other-religion potters and the averaged (across 100 replications) simulated cumulative adoption curve generated by 32 different agent-based models (x-axis), under different interaction rates (y-axis). (for more details, see figure's 6 legend)

Thus taken as a whole these agent-based simulations tell us two main things. First, whilst within the Indian social contexts, supposing that dyadic family ties transmitted information about 
the innovation, and it was necessary to generate simulated aggregate diffusion curves resembling the empirical ones, within the Kenyan social context, physical (rather than relational) distances seem sufficient to sustain the contagion dynamic underlying the diffusion process. This difference seems consistent with the fact that, unlike the Indian case, Kenyan potters are few in number, all live in very small areas - Kiriri and Ngararigeri being only 5 kilometers apart (compared to Indian Muslim and Hindu villages that are located at average distances of about 63 kilometers and 108 Kilometers respectively from each other) -, and all attend the same local market every week. In this sense Kenyan potential adoptees can be "hit" by adopters independently from the relational distance (in terms of family network) separating them. Simulations also tell us a second thing, however. Once a potential adopter is reached by information about the innovation, in both social contexts, it was necessary to postulate that the adoption decisions of potters' relatives matter in order to generate realistic diffusion curves. In particular in three sub-cases, namely Indian Muslims, Indian Hindus, and Kenyan Mukurinos, we needed to consider the width of the bridge connecting the adopter's and potential adopters' direct relatives, plus the choices made by relatives involved by that bridge. In one case (i.e. other-religion potters), the width of the bridges were sufficient on their own.

\section{Understanding the simulated dynamics}

The simulation analysis we have just commented on led to a parsimonious result. It shows that a common network-level feature must be taken into consideration to reproduce the observed diffusion curves within all the four religious sub-groups under scrutiny. This network feature is the width of the bridge connecting the potential adoptee's and adopter's direct relatives. This result is, however, somewhat counter-intuitive. Why indeed should model variants containing the width of the bridges be necessary to account for cases of both fast and slow diffusion?

One cannot argue that, to use a metaphor, it is as if in a race car, four teams (our four religious sub-groups) were competing to drive the same car (the model) equipped with differently powered engines (where the engine is the network and its power comes from its structure). The metaphor would indeed work for the Indian case - where the sub-group (i.e. Muslim potters) with the powerful engine (i.e wide bridges) corresponds to the sub-group where diffusion was more rapid - but would not work for the Kenyan case — where the sub-group presenting faster diffusion is not the one with the most powerful engine (Mukurino potters are indeed related by smaller bridges compared to other-religion potters).

The metaphor also poses a second problem. It would work fine if all that mattered was the size of the bridge so that, the larger (smaller) the bridge, the higher (lower) is the adoption 
probability of the actor embedded in the bridge concerned. But, as we have seen, simulations for Muslim, Hindu, and Mukurino potters in fact require a more refined decision mechanism, where the proportion of adopters involved by the bridge also matters. This is a subtle but important difference. In fact, making the proportion of previous adopters enter the agents' decision function implies that the proportion of non-adopters also has en effect (on this point, see Centola and Macy 2007: 711). As a consequence, the same bridge, depending on whether it has plenty of adopters or non adopters, will push the diffusion dynamics toward fast or slow diffusion. Thus in these model variants it is not only the size of the bridge that matters but also who is on the bridge in terms of adopters and non adopters. In other word, to continue the car metaphor, the type of the fuel introduced into the engine also plays a role.

In our simulated potter populations, the "fuel" differs across religious sub-groups and it modifies the expected structural effect of the width of the bridges. The most telling contrast is given by, on the one hand, simulated Indian Muslim potters, and, on the other, simulated Kenyan Mukurino potters. Among the former, a group of early adopters, very well connected across villages through family ties, are likely, at the very beginning of the simulated process, to be involved in some of the (large) bridges relating their family neighborhood to that of the potential adopters they select. This will increase the probability of the selected potential adopters to adopt themselves, which, at the following iteration, will increase slightly more the probability that bridges will be filled by new adopters, who will further increase the probability that the selected potential adoptees adopt themselves, which in turn will increase the overall proportion of adopters who are likely to be on the bridges, and so on. In other words, a very small initial critical mass of adopters on the bridges triggers a cascade that, at each iteration, increases the proportion of adopters available on the bridges. Despite being related by a family network containing less and smaller bridges, the simulated Kenyan Mukurino potters are able to sustain a similar cumulative process. The few existing early-adopters among them start filling the existing bridges, which, although small, progressively help sustain the adoptions of more and more potters. In other words the artificial Mukurino potters did a lot (individual behavior) with limited resources (network structure).

Thus our empirically-grounded agent-based models have complemented the network-oriented empirical analysis showing in silicio that wide bridges can equally lead to fast or slow diffusion depending on the role early-adopters play in the initial stages of the diffusion process. When they send positive signals about the innovation, even small bridges can sustain diffusion virtually to the entire population (as in the case of Kenyan Mukurino potters). By contrast, when early-adopters send negative signals about the innovation, even wide bridges do not 
necessarily lead to fast diffusion because locally overlapping social circles can only help non adopters reciprocally to reinforce their doubts, hence their negative choices (as with our Kenyan other-religion potters).

\section{Conclusion}

Why do different groups of actors, who are as equally aware of the advantages of a given new practice as each other, adopt it at a different pace? Within the context of ethnically and/or religiously heterogeneous social contexts, research in anthropological archeology is full of such puzzles with respect to technological and stylistic innovations, both in the short and the long term, in a variety of areas of the world (see Roux 2012; Roux et al., 2017).

In this paper, we have documented two new cases of diffusion dynamics in North-west India and central Kenya in the field of pottery. In the former case, the updraft kiln was introduced in the Jodhpur region by a Muslim (male) potter in 1987 but this tool then spread very differently among the Muslim and Hindu potters inhabiting the region. In the latter case, a new form of pot (i.e. flat based pots) were introduced in the Ishiara region in 1997 by an Apostolic (female) potter but its adoption also followed different routes among Mukurino and Apostolic potters. Our aim was to explain the observed differences in the rates of adoption across religious sub-groups. The puzzling character of these differences comes from the fact that, in both social contexts, although potters from different religious sub-groups were exposed to the same market conditions, had similar cost-benefit ratios, and were equally motivated to innovate, one group (Muslim and Mukurino potters, respectively) adopted much faster and more widely than the other.

To account for these differences, we adopted a structural approach and derived inspiration from the recent debates on what type of ties (strong versus weak) and related network features (local redundancy versus reachability) and adoption mechanism (complex versus simple contagions) appear to matter the most to sustain more rapid and wider diffusion (for an overview of this debate, see Centola 2018). We posited an analytical framework where both types of ties are supposed to contribute to explain the whole diffusion process but at different stages and with different roles. More specifically, we hypothesized that weak ties are crucial initially to increase the probability that some actors become aware of the innovation but then network features of strong ties are essential to sustain the diffusion process once the innovation has entered the system under scrutiny. Our empirical data was ideal to assess this working hypothesis because it made it possible to clearly separate weak from strong ties.

As to weak ties, we found indeed that, in both social contexts, the diffusion process was 
initiated by some potters who had learned about the existence and the internal functioning of the innovations through sporadic, contingent, accidental, ephemeral, and, in the vast majority of cases, heterophilious social contacts. Weak ties through which potters become in contact with exogenous injection points brought novelty to the regions under study, thus making the beginning of the diffusion process possible. As to strong ties, Indian and Kenyan kinship networks delivered an interesting, and unexpected, case of natural variation. In particular, we found that, while Muslim potters (i.e. the Indian religious sub-group where diffusion of the kiln was faster and wider) corresponded to the group where family ties were more reachable and locally redundant, whilst kinship ties among Mukurino potters (i.e. the Kenyan sub-community where diffusion of flat-base pots was faster and wider) actually were not more reachable, nor more locally redundant, than those characterizing potters from other religions, among whom the diffusion of flat based pots was slower. This observation runs counter to common assumptions that networks containing many "brokers" will make the transmission of the information easier (see Valente 1999) or that "(...) the lack of 'wide bridges' in social networks can significantly inhibit the level of adoption in a population (...)"(Centola 2011: 1271).

To make this explanans-level puzzle understandable, we further extended our empirical investigation of strong ties among Indian and Kenyan potters by studying the correlation between these ties and advice networks. In both social contexts, we found that early-adopters whom, we could document, corresponded to the most central actors in the kinship networks and to high-level expert potters (see, on this point, Roux et al. 2018), were fully involved in the circulation of advice and help only within the groups where diffusion was more rapid and wider. It is on this basis that we ultimately argued that network reachability and local redundancy (in terms of large bridges) in fact constitute diffusion facilitators provided high-level expert, and early-adopter potters are fully involved in the person-to-person learning process, thus spreading the best information and most positive signals in favor of the to-be-adopted trait. If this is not the case, high network reachability and local redundancy will spread and reinforce doubt and uncertainty, rather than favorable opinions, thus leading to slower, not faster, diffusion.

This argument was supported by our qualitative evidence. Indian Muslim potters presented all the desirable features. They are a group of skilled and very active early adopters who are well connected across villages through family ties and are embedded in large local family bridges. They have triggered a self-reinforcing cascade of positive signals that fostered adoptions leading to rapid and almost full diffusion. Kenyan Apostolic potters are (qualitatively) comparable to Indian Muslim potters in terms of network topology. They had great structural opportunities, in terms of 
brokerage and potential local reinforcement, but early-adopters were not fully involved in the diffusion process, and, of those who did adopt, they in fact only learned by themselves. Thus, in this case, what could only emerge in overlapping local circles were doubts about whether to adopt or not. Kenyan Mukurino potters experienced a symmetrical situation. They were connected by a less searchable and locally redundant kinship network but the most central potters received high-quality training and were really involved in the circulation of advice and help, thus making information of good quality move through the network. In other words, they did a lot with limited resources. Finally, Indian Hindu potters presented the least favorable configuration. They were embedded in a weakly reachable family network, also characterized by narrow local bridges; in addition, a group of poorly connected early adopters sent contradictory signals to their community about the advantages of the kiln. Uncertainty, thus lower adoption probability, could only solidify within this religious sub-group.

Aware of the correlational nature of our empirical investigation and the fragmentary character of our qualitative narratives, we finally decided to provide further support to our argument by creating a diffusion process in silicio through agent-based computer simulations where the network structure relating artificial agents corresponded to the observed kinship networks (a feature that is still very rarely seen in existing agent-based models, see Smith and Burow 2018). These simulations led to an important result. To generate the most realistic diffusion curves in each of the four religious sub-groups, it was necessary to design a micro-level decision-making mechanism in which the potter's adoption decisions were influenced by the width of the bridge connecting her/his direct family relatives to those of the adopter who made her/him aware of the innovation. In addition, simulations for Muslim, Hindu, and Mukurino potters required a more refined decision-making mechanism, where the proportion of adopters involved in the bridge was also taken into account. This offers additional and subtle theoretical evidence suggesting that the macroscopic effect of local redundancy in fact depends on whether bridges are rich in adopters or non adopters, so that, depending on the initial signal present in the network, large (small) bridges can equally lead as much to either fast or slow diffusion.

Simulation results also help to show that our main result is generalizable beyond the specific social and cultural context we have studied. In its abstract form, this result can by formulated in the following terms. When the adoption of a new practice requires positive reinforcement from several previous adopters (our scope condition), if early-adopters occupy central positions within the relevant social network for the transmission of the information (trigger condition 1) and they possess qualities that are related to the innovation at hand (trigger condition 2), then, depending on 
the real involvement of these early-adopters in the circulation of advice (modifier), structural features that are usually regarded as diffusion facilitators (namely, network reachability and local redundancy) can equally lead to high or low rates of diffusion of the new practice (macroscopic outcome). The formal structure of our argument clearly is independent of the specific innovation at hand, the type of actors, and the social traits (or mechanisms) that create by-group network difference. Only scope and trigger conditions should be met. If so, our argument is testable in other social contexts and on a larger scale.

Let us finally stress again that we could only arrive at this result by combining qualitative data, network analysis, and simulation models, a combination of methods that also has the potential to contribute to meta-theoretical debates in ethnography, sociology, and archeology. In particular, the loop that we have established between qualitative field observations, network analysis, and computational simulation well illustrates recent claims about how ethnography can scale-up through formal methods (Abramson et al. 2017). The way we built on this combination of approaches to identify the social mechanisms at work also exemplifies the full research path at the heart of a certain version of so-called analytical sociology (for an overview, see Manzo 2014b; Kalter and Kroneberg 2014; Léon-Medina 2017), and demonstrates that this perspective is not only compatible with big-data approaches (for a recent statement, see Keuschnigg et al. 2017) but can equally well guide qualitatively-oriented, small-N studies. Finally, our paper shows that ethnoarcheology, when coupled with refined quantitative methods, and simulation techniques, is indeed able to identify robust generative causal patterns that can serve as explanatory building blocks for comparable contexts for which all required empirical information may not be available (for a recent debate, see Gosselain 2016; Roux 2017).

\section{Acknowledgements}

This work was supported by the ANR (The French National Agency for Research) within the framework of the program CULT (Metamorphosis of societies - "Emergence and evolution of cultures and cultural phenomena"), project DIFFCERAM (Dynamics of spreading of ceramic techniques and style: actualist comparative data and agent-based modeling) (nºAN-12-CULT-0001-01). In India, the support of the Rupayan Sansthan was invaluable. We are grateful to Kuldeep Kothari for resolving all the logistical problems as well as Meet Kaur Gulati, Anil Sharma, Ira Sisodia and Lakshman Diwakar for their assistance in the field. In Kenya, we are grateful to Jacqueline Kawira for her assistance in the field. Last but not least, we would also like to thank all the Indian and Kenyan potters for their availability and their unfailing kindness. Earlier 
drafts of this paper were presented at the INAS conferences in Mannheim (2014) and Utrecht (2016), at the conference "Diffusion of Innovation: Social boundaries and networks" at the University of Paris-Sorbonne, as well as at several research seminars in Norrköping (2016), Oxford (2016), Konstanz (2016), Paris (2017), and La Rochelle (2017). We thank participants for their helpful comments. Mohamed Cherkaoui, Ivan Ermakoff, Cyril Jayet, and Jörg Stolz read earlier versions of the manuscript and provided instructive written remarks. We also thank JAMT referees for their invaluable critical feedback. Usual disclaimers apply.

\section{References}

Abramson, C. M., Joslyn, J., Rendle, K. A., Garrett, S. B., \& Dohan, D. (2017). The promises of computational ethnography: Improving transparency, replicability, and validity for realist approaches to ethnographic analysis. Ethnography. doi.org/10.1177/1466138117725340.

Aral, S., Van Alstyne, M. (2011). The Diversity-Bandwidth Trade-off. American Journal of Sociology, 117(1), 90-171.

Baldassarri, D. (2015). Cooperative Networks: Altruism, Group Solidarity, Reciprocity, and Sanctioning in Ugandan Farmer Organizations. American Journal of Sociology, 121(2), 355-395.

Banerjee, A., Chandrasekhar, A. G., Duflo, E., Jackson, M. O. (2013). The Diffusion of Micro-finance. Science. doi: 10.1126/science.1236498.

Beggs, J. J., Haines, V. A., \& Hurlbert J. S. (1996) Revisiting the Rural-Urban Contrast: Personal Networks in Nomnetropolitan and Metropolitan Settings. Rural Sociology, 61(2), 306-325.

Bittles, A. H., \& Hussain, R. (2000). An analysis of consanguineous marriage in the Muslim population of India at regional and state levels. Annals of Human Biology, 27(2), 163-171.

Böhm, T., \& Hillmann, H. (2015). A Closed Elite? Bristol's Society of Merchant Venturers and the Abolition of Slave Trading. Political Power \& Social Theory, 29, 147-175.

Borgatti, S. P., Everett, M. G., \& Johnson, J. C. (2013). Analyzing social networks. London: SAGE Publications Limited.

Boudon, R. (1986). Theories of Social Change: A Critical Appraisal. Berkeley and Los Angeles: University of California Press.

Boudon, R. (2003. Beyond rational choice theory. Annual Review of Sociology, 29, 1-21.

Boudon, R. (2014). What is Context? Köln Z Soziol (Suppl), 66, 17-45. 
Bruch, E., \& Atwell J. (2015) Agent-Based Models in Empirical Social Research. Sociological Methods and Research, 44(2), 186-221.

Centola, D. (2010). The Spread of Behavior in an Online Social Network Experiment. Science, 329, 1194-7.

Centola, D. (2011). An Experimental Study of Homophily in the Adoption of Health Behavior. Science, 334, 1269-72.

Centola, D. (2015). The Social Origins of Networks and Diffusion. American Journal of Sociology, 120(5), 1295-1338.

Centola, D. (2018). How Behavior Spreads: The Science of Complex Contagion. Princeton (NJ): Princeton University Press.

Centola, D., Eguiluz, V., \& Macy, M. (2007). Cascade Dynamics of Complex Propagation. Physica A, 374, 449-456.

Centola, D., \& Macy, M. W. (2007). Complex contagions and the weakness of long ties. American Journal of Sociology, 113(3), 702-734.

Clarke, D. L. (1968). Analytical archaeology. London: Methuen \& Co ltd.

Coleman, J. S., Katz, E., \& Menzel H. (1957). The diffusion of an innovation among physicians. Sociometry, 20(4), 253-270.

Davis, D. D. (1983). Investigating the diffusion of stylistic innovations. Advances in Archaeological Method and Theory, 6, 53-89.

Deffuant, G., Huet, S., \& Amblard, F. (2005). An Individual-Based Model of Innovation Diffusion Mixing Social Value and Individual Benefit. American Journal of Sociology, 110(4), 1041-69.

Delre, S. A., Jager W., Bijmolt T. H. A., \& Janssen M. A. (2010). Will It Spread or Not? The Effects of Social Influences and Network Topology on Innovation Diffusion. Journal of Product Innovation Management, 27(2), 267-282.

DiMaggio, P., Garip, F. (2012). Network Effects and Social Inequality. Annual Review of Sociology, 38, 93-118

Erikson, E. (2017). Social Networks and Macrosocial Change. Annual Review of Sociology, 43, 229-248.

Ermakoff, I. (2017). On the Frontiers of Rational Choice. In C. Benzecry, M. Krause, \& I. A. Reed (Eds.), Social Theory Now (pp. 162-200). Chicago: The University of Chicago Press. 
Fink, C., Schmidt, A., Barash, V., Kelly, J., Cameron, C., \& Macy, M. (2016). Investigating the Observability of Complex Contagion in Empirical Social Networks. In International AAAI Conference on Web and Social Media.

https://www.aaai.org/ocs/index.php/ICWSM/ICWSM16/paper/view/13143. Accessed 18 December 2017

Ganguli, K. K. (1983). Cultural History of Rajasthan. Delhi, India: Sundeep Prakashan.

Gee, L. K., Jones, J., Burke, M. (2017). Social Networks and Labor Markets: How Strong Ties Relate to Job Finding on Facebook's Social Network. Journal of Labor Economics, 35(2), 485-518.

González-Bailón, S., Borge-Holthoefer, J., \& Moreno, Y. (2014). Online Networks and the

Diffusion of Protest”. In G. Manzo (Ed.), Analytical Sociology: Actions and Networks (pp. 263-279).

Chichester: Wiley and Sons.

Gosselain, O. P. (1992). Bonfire of the enquiries. Pottery firing temperatures in archaeology: What for? Journal of Archaeological Science, 19(3), 243-259.

Gosselain, O. P. (2016). To hell with ethnoarchaeology. Archaeological dialogues, 23(2), 215-228.

Granovetter, M. (1978). Threshold Models of Collective Behavior. American Journal of Sociology, 83(6), 1420-1443.

Granovetter, M. (1973). The strength of weak ties. American Journal of Sociology, 78(6), 1360-1380.

Hägerstrand, T. (1971). A Monte Carlo Approach to Diffusion. European Journal of Sociology, 6(1), 43-67.

Hamberg, K., Houseman, M., White, D. R. (2011). Kinship Network Analysis. In J. Scott, P. J. Carrington (Eds.), The Sage Handbook of Social Network Analysis (pp. 533-549). London: Sage. Hamberg, K., Gargiulo, F. (2014) Virtual Fieldwork: Modeling Observer Bias in Kinship and Marriage Networks. Journal of Artificial Societies and Social Simulation, 17(3), 2.

Hanneman, R. A., \& Riddle, M. (2011). A Brief Introduction to Analyzing Social Network Data. In J. Scott, P. J. Carrington (Eds.), The Sage Handbook of Social Network Analysis (pp. 331-339). London: Sage.

Hollstein, B. (2011). Qualitative Approaches. In J. Scott, P. J. Carrington (Eds.), The Sage Handbook of Social Network Analysis (pp. 404-416). London: Sage.

Iyengar, R., Van den Bulte, C., \& Valente, T. W. (2011). Opinion Leadership and Social Contagion in New Product Diffusion. Marketing Science, 30(2), 195-212. 
Kadushin, C. (2012). Understanding Social Networks. Theories, Concepts, and Findings. NY: Oxford University Press.

Kalter, F., \& Kroneberg, C. (2014). Between mechanism talk and mechanism cult: new emphases in explanatory sociology and empirical research. Kölner Zeitschrift für Soziologie und Sozialpsychologie, 66 (Suppl 1), 91-115.

Keuschnigg, M., Lovsjö, N. \& Hedström, P. (2017). Analytical sociology and computational social science. Journal of Computational Social Science. doi.org/10.1007/s42001-017-0006-5.

Kramer, C. (1997). Pottery in Rajasthan. Ethnoarchaeology of two Indian cities. Washington and London: Smithsonian Institution Press.

Krings, G., Calabrese, F., Ratti, C., \& Blondel, V. (2009). Urban Gravity: A Model for Inter-City Telecommunication Flows. Journal of Statistical Mechanics: Theory and Experiment, L07003.

Lambiotte, R., Blondel, V. D., de Kerchove, C., Huens, E., Prieur, C; et al. (2008). Geographical dispersal of mobile communication networks. Physica A: Statistical Mechanics and its Applications, $387(21), 5317-5325$.

Lazega, E., Pattison, Ph. E. (1999). Multiplexity, generalized exchange and cooperation in organizations: a case study. Social networks, 21(1), 67-90.

Léon-Medina, F. J. (2017). Analytical Sociology and Agent-Based Modeling: Is Generative Sufficiency Sufficient? Sociological Theory, 35(3), 157-178.

Livingstone, S. A. (2001). Bonfire II: The Return of Pottery Firing Temperatures. Journal of Archaeological Science, 28(9), 991-1003.

Manzo, G. (2014a). The Potential and Limitations of Agent-based Simulation: an Introduction. Revue Française de Sociologie, 55(4), 653-688.

Manzo, G. (2014b). Data, generative models, and mechanisms: more on the principles of analytical sociology. In G. Manzo (Ed.), Analytical sociology: actions and networks (pp. 4-52). Chichester: Wiley. Miller, D. (1985). Artefacts as categories. A study of ceramic variability in Central India. Cambridge: Cambridge University Press.

Milner, M. (1988). Status Relations in South Asian Marriage Alliances: Toward a General Theory. Contributions to Indian Sociology, 22(2), 145-169.

Mitschele, A. (2014). Identity and Opportunity in Early Modern Politics: How Job Vacancies Induced Witch Persecutions in Scotland, 1563-1736. In G. Manzo (Ed.), Analytical Sociology: Actions and Networks (pp. 151-169). Chichester: Wiley and Sons. 
Opp, K.-D. (1999). Contending conceptions of the theory of rational action. Journal of Theoretical Politics, 11(2): 171-202.

Padgett, J. F., \& Ansell, C. K. (1993). Robust Action and the Rise of the Medici, 1400-1434. American Journal of Sociology, 98(6), 1259-1319.

Palloni, A. (2001). Diffusion in Sociological Analysis. In J. B. Casterline (Ed.), Diffusion Processes and Fertility Transition: Selected Perspectives (pp. 66-115).Washington, DC: National Academy Press.

Railsback, S. F., \& Grimm, V. (2011). Agent-Based and Individual-Based Modeling: A Practical Introduction. Princeton (NJ): Princeton University Press.

Rao, G. A., Rogers E. M., \& Singh S. N. (1980). Interpersonal Relations in the Diffusion of an Innovation in Two Indian Villages. Indian Journal of Extension of Education, 16(1-2), 19-24.

Rivera, M. T., Soderstrom, S. B., \& Uzzi, B. (2010). Dynamics of Dyads in Social Networks: Assortative, Relational, and Proximity Mechanisms. Annual Review of Sociology, 36(1), 91-115.

Robins, G. (2015). Doing social network research: Network-based research design for social scientists. London: Sage.

Robins, G. (2011). Exponential Random Graph Models for Social Networks. In J. Scott \& P. J. Carrington (Eds.), The Sage Handbook of Social Network Analysis (pp. 484-501). London: Sage.

Rogers, E. M. (2003, $5^{\text {th }}$ ). Diffusion of Innovations. NY: Free Press.

Rossman, G., Chiu, M. M., \& Mol, J. M. (2008). Modeling Diffusion of Multiple Innovations via Multilevel Diffusion Curves: Payola in Pop Music Radio. Sociological Methodology, 38, 201-230.

Roth, C., Gargiulo, F., Bringé, A., \& Hamberg, K. (2013). Random Alliance Networks. Social Networks, 35(3), 394-405.

Roux, V. (2012). Spreading of Innovative Technical Traits and Cumulative Technical Evolution: Continuity or Discontinuity? Journal of Archeological Method and Theory, 20(2), 312-330.

Roux, V. (2015). Standardization of ceramic assemblages: Transmission mechanisms and diffusion of morpho-functional traits across social boundaries. Journal of Anthropological Archaeology, 40, 1-9. Roux, V. (2017). Not to throw the baby out with the bathwater. A response to Gosselain's article. Archaeological Dialogues, 24(2), 225-229.

Roux, V., Bril B., \& Karasik, A. (2018). Weak ties and expertise: crossing technological boundaries. Journal of Archaeological Method and Theory.

Rowe, W. L. (1960). The Marriage Network and Structural Change in a North Indian Community. 
Southwestern Journal of Anthropology, 16(3), 299-311.

Ryan, B., \& Gross, N. C. (1943). The Diffusion of Hybrid Corn in Two Iowa Communities. Rural Sociology, 8(1): 15-24.

Saraswati, B. (1979). Pottery-Making Cultures and Indian Civilization. New Delhi, India: Abhinav Publications.

Smith J. A. \& Burow J. (2018). Using Ego Network Data to Inform Agent-based Models of Diffusion. Sociological Methods and Research, 1-46. doi: 10.1177/0049124118769100.

Snijders, T. A. B. (2011). Network Dynamics. In J. Scott \& P. J. Carrington (Eds.), The Sage Handbook of Social Network Analysis (pp. 501-514). London: Sage.

Stovel, K., \& Shaw, L. (2012). Brokerage. Annual Review of Sociology, 38, 139-158.

Strang, D., \& Soule, S. A. (1998). Diffusion in Organizations and Social Movements: From Hybrid Corn to Poison Pills. Annual Review of Sociology, 24, 265-290.

Tubaro, P., \& Casilli, A. A. (2010). “An Ethnographic Seduction”: How Qualitative Research and Agent-based Models can Benefit Each Other. Bulletin of Sociological Methodology/Bulletin de Méthodologie Sociologique, 106(1), $59-74$.

Valente, T. W. (1999, 2nd). Network Models of the Diffusion of Innovations. New York: Hampton Press. Valente, T. W., \& Davis, R. L. (1999) Accelerating the Diffusion of Innovations Using Opinion Leaders. Annals, AAPSS, 566, 55-67.

Van den Bulte, C., and Lilien, GL. (2010). Medical innovation revisited: Social contagion versus marketing effort. American Journal of Sociology, 106(5), 1409-1435.

van Duijn, M. A. J., \& Huisman, M. (2011). Statistical Models for Ties and Actors. In J. Scott \& P. J. Carrington (Eds.), The Sage Handbook of Social Network Analysis (pp. 459-484). London: Sage.

Watts, D. J. (1999). Networks, dynamics, and the Small-World phenomenon. American Journal of Sociology, 105(2), 493-527.

Watts, D. J. (2004). The new science of networks. Annual Review of Sociology, 30, 243-270.

Watts, D. J., Doods, P. S. (2007). Influentials, Networks, and Public Opinion Formation. Journal of Consumer Research, 34, 441-458.

Watts, C., \& Gilbert, N. (2014). Simulating Innovations. London: Edward Elgar Publishing. Watts, D. J., \& Strogatz, S. H. (1998). Collective dynamics of 'Small-world' networks. Nature, 393, $440-442$. 
Wejnert, B. (2002). Integrating Models of Diffusion of Innovations: A Conceptual Framework. Annual Review of Sociology, 28, 297-326.

White, D. R., \& Houseman, M. (2003). The Navigability of Strong Ties: Small Worlds, Tie Strength, and Network Topology. Complexity, 8(1), 72-81.

White, D. R., \& Johansen, U. (2006). Network Analysis and Ethnographic Problems: Process Models of a Turkish Nomad Clan. Lanham (Maryland): Lexington Books.

Young, P. (2006). The Diffusion of Innovations in Social Networks. In L. E. Blume, \& S. N. Durlauf (Eds.),The Economy as a Complex Evolving System, vol. III. Oxford: Oxford University Press. Young, P. (2009). Innovation Diffusion in Heterogeneous Population: Contagion, Social Influence, and Social learning. American Economic Review, 99(5), 1899-1924.

Young, P. (2011). The Dynamics of Social Innovation. Proceedings of the National Academy of Sciences, 108(4), 21285-21291.

\section{A. Ethnographic appendix}

A.1/ In the Jodhpur region, we visited 18 rural villages and 1 urban center (Jodhpur). Some of these villages are inhabited only by Hindu potters (Bisalpur, Jodhpur, Sathin, Pachpadra); some others only by Muslim potters (Sar, Salawas, Rudakali, Tanawra, Sangasni, Ramasni, Rohat, Dhava, Banjara, Boranada Basni); still others are mixed (Siwana, Mokalsar, Banar, Palasni). The villages' sizes range from those where only one potter household is present (as in Bipalsur) to larger villages with 40 active potters (such as Banjara, Ramasni or Pachpadra) - on average, 14 potter households were active in the villages under scrutiny. Among mixed villages, the Muslim/Hindu ratio also differs: in Banar, Muslim potters are in the overwhelming majority (14 versus 1); in Mokalsar the reverse holds (3 versus 10); Siwana and Palasni present a much more balanced ratio (2[1] Muslims versus 3[2] Hindus, respectively).

A.2/ Excerpts of Interviews with Indian potter. (From interview with BIK in Sar) In 1987, BIK, Talu's son, had a brother-in-law who used to work in Ahmedabad and who informed him about possible well paid seasonal work. So, he went to Ahmedabad, and worked for a few months in workshops run by Hindu potters. He discovered how to use the kiln there. When he came back, he decided to build one of them because it was less effort and more rapid than the open firings. (From interview with Fakhir in Salawas) FAK was the first one to adopt the kiln in 1987. He saw the kiln when he went to Sar to meet relatives. BIK had just built it; (From interview with BIE in Sangasmi). The adoption of the kiln started in Sangasni in 1990 with 2 potters, BIE and HAN, who had relatives in Salawas. After discussing with CHA, brother-in-law of HAN and cousin of BIE, CHA came to Sangasni to help 
them to build the kiln; (From interview with RAM in Banar) In 1990, RAM, son of NUR, 20 years old, went to Ahmedabad to sell pots. Over there, he saw the kiln and the Hindu potters explained to him how it worked. However he did not adopt it even though he could see advantages. In 1996, he went to Salawas for the wedding of the youngest sister of his father. During this social event, he met CHA who agreed to come to Banar to help him build the kiln. (From interview with GAN in Ramasani) The kiln was adopted in 1995 by 4 households at a time (SAD, MOH, UZI and GAN). They went to Salawas for a family event. They saw the kiln, and found that it was much faster than open firing. They asked IDU from Salawas to come to Ramasani to make the kilns. IDU came, made the kilns and showed them how to make the firing. He made a demonstration attended by dozen potters.

A.3/ Marriage rules. Both the Muslim and the Hindu potters are endogamous communities, patrilineal and virilocal (see Saraswati 1979; Ganguli 1983). They practice village exogamy, with the brides usually leaving their natal communities to join their grooms' households. As a general rule, these brides originate from families which do not have a patrilineal link with the groom's family the families the daughter can, and cannot, marry with are called genait and bhaipa, respectively. Despite these common rules, significant differences exist in the marriage rules between the two communities. As for the Muslim potters, they descend, in each village, from a common, well identified ancestor, who was usually born in one of the neighboring villages -for instance, Boranada Basni is the village ancestor of Salawas (11 km away) which is the village ancestor of Sar (10 km away). Muslim potters preferentially marry maternal first cross-cousins, a general rule in the Indian Muslim communities (Bittles and Hussain 2000). This preferential marriage rule goes hand in hand with the exchange of women between genait villages, which enables Muslim potters to maintain symmetrical alliances and avoid differences of status between wife-givers and wife-takers. Hindu potters are embedded in a different social structure and have different marriage rules. They belong to three main sub-castes, the Banda, the Purubiya and the Maru (the latter being present nowadays only in Jodhpur). These three sub-castes are endogamous, implying that there cannot be kinship ties between Purubiya and Banda (and Maru). Each of these sub-castes is in turn subdivided into gotras, or clans, which are exogamous. Several sub-castes can inhabit the same place, but, as a general rule, marriage alliances are made in different villages and sometimes with remote villages where only one alliance will occur (for instance, the brothers of a same family will marry women from different places) (Kramer 1997). Among the surveyed villages, Pachpadra is a good illustration. Two subcastes, the Purubiya and the Banda, each of them sub-divided into three gotras, co-exist, and a sample of 31 brides we could carefully investigate show that the brides come from 24 different villages, the majority located more than $60 \mathrm{~km}$ away. As a consequence, kinship connections within the Hindu community typically involve large marriage networks at a regional 
level but with no concentration of ties within a given village, and sparse and weak family relationships across villages (Rowe 1960). The absence of regular visits between families, which contrasts with the frequent encounters at family events within the Muslim community, testifies of distended relationships between wife-givers and wife-takers, with no reciprocal relationships and perhaps the desire in some cases for no interference from in-laws (Miller 1985).

\section{B. Methodological appendix}

B.1/ Bridge width. To capture the width of the bridges, we implemented (in NetLogo) the following procedure: for each pair of potters $i$ and $j$ who are not directly related, $1 /$ we select the direct (i.e. 1-step) neighbors of $i ; 2 /$ we select the direct (i.e. 1-step) neighbors of $j ; 3 /$ we select the neighbors of the neighbors of $i$ (i.e. neighbors of $i$ at distance 2); 4/ we count how many neighbors of the neighbors of $i$ are neighbors of $j$. This last operation indirectly makes it possible to retrieve the number of links between the neighborhoods of the two disconnected potters because, when 2-step neighbors of $i$ are also 1-step neighbors of $j$, only one of the two cases is verified: either the 1-step neighbor of $i$ has a link to one of the 1-step neighbor of $j$, or the 1-step neighbor of $i$ is also a 1 -step neighbor of $j$ (which is the case of the common neighbor appearing in Centola and Macy's definition, 2007: 713).

B.2/ Data limitation -Family networks. Complete family trees were directly reconstructed with all interviewees, and, when ties beyond the limits of the surveyed households were mentioned, they were systematically double-checked, sometimes through quick questions, with potters living in the village concerned by these declarations. Our ability to travel within the Jodhpur region over a period of three years thus considerably limited observation biases usually present in the mapping of kinship connections (for a deep analysis of these problems, see Hamberg et al. 2011; Roth et al. 2013; Hamberg and Gargiulo 2014). The only simplification we introduced in our analysis is that we did not distinguish between different types of family ties so that, for instance, a cousinship and a brother-in-law relationship are regarded as equally relevant for the circulation of information about the kiln. Our qualitative evidence was indeed insufficient to formulate more specific hypotheses in this respect.

B.3/ Bridge fraction. Unless we are mistaken, Centola (2015: 1318) did not make explicit how he computed the "fraction of neighborhoods in the network with at least one 'wide bridge' to another neighborhood". More specifically, the problem is how to compute the denominator of this "fraction". For us, the most coherent way to compute that "fraction" is by making the denominator the potential number of not-directly-connected pairs of nodes in the network, which corresponds 
to the total number of possible dyads $\left(\mathrm{N}^{*}(\mathrm{~N}-1)\right)$, minus the number of observed ties in the network. The computation of the total number of possible dyads does not include the usual division by 2 for symmetric ties for the following reason: although the kinship network is symmetric, the width of the bridge between a given pair of not-directly-connected nodes $i$ and $j$ is not necessarily the same for the two nodes. In particular, as long as the number of neighbors at distance 1 of $i$ and $j$ differ, the node with the smallest number of neighbors at distance 1 is structurally likely to have the narrowest bridge.

B.4/ Data limitation - Advice networks. Compared to our family networks, it must be acknowledged that information about advice is more fragile. The advice networks we reconstructed are a rough approximation of the unobservable influence process to which potters were likely to be exposed. In this respect, let us first note that we did not have access to the complete ego-centered networks (of a randomly selected sample of potters) on several dimensions (for such an exceptional design, see Banerjee et al. 2013). Second, we did not have access to fine-grained time-stamped advice exchanges. For instance, when a potter is described as being invited to give a public demonstration attended by a certain number of potters, as in the excerpt above from Ramasani (see appendix A.1), we attribute to this potter the role of main "influencer", though some of the potters attending the demonstration adopted several months (or years) later, thus suggesting that in fact interactions following the demonstration may (also) have played a role in the decision process. Because of these limitations -which indeed are common in network studies relying on historical or qualitative data (see, for instance, Böhm and Hillmann 2015: 168; Mischele 2014; Hollstein 2011)-, we decided not to estimate complex multivariate statistical models for network configuration (Robins 2011) and/or evolution (Snijders 2011) or individual-level models with network covariates relating potters' time of adoption to their positions in the advice network (van Duijn and Huisman 2011; see also Valente 1999: ch. 8).

B.5/ QAP correlations. Taking inspiration from analyses on multiplex networks (for two remarkable illustrations with respect to marriage and business ties, and advice and friendship connections, see, respectively, Padgett and Ansell 1993, and Lazega and Pattison 1999), we first quantify the proportion of pair of potters for which an advice and a family tie was observed at the same time. Among Indian Muslim potters, $96 \%$ of advice ties correspond to a family tie; among Indian Hindu potters, $60 \%$ of advice ties are also family ties; among Kenyan Mukurino and other-religion potters (as before considered as a single network because mixed-religion diffusion ties are present), 55\% of advice ties are also family ties. Then, quadratic assignment procedure (QAP) correlations were used to test for the robustness of these counts (for a description of this method, see Borgatti et al. 2013: 128-129; Robins 2015: 190-191). QAP correlations for Muslim, Hindu, and, on the other hand, Mukurino and other-religion potters are, respectively, $0.254(\mathrm{p}<0.001), 0.247(\mathrm{p}<0.001)$ and 0.08 
$(\mathrm{p}=0.07)$. If one considers the meaning of the $\mathrm{p}$-value within the quadratic assignment procedure -that is, the proportion of randomly permutated networks for which one finds the same correlation observed on the empirical networks-, then it seems reasonable to consider that, although the result is slightly less spectacular for Kenyan networks, it is highly unlike that the observed overlap in both social contexts between advice and kinship ties is due to chance or structural constraints only. (QAP correlations were computed through the function "qaptest" in R package "sna", and double-checked through a program we wrote in Java from scratch).

B.6/ Simulated time and interaction rate (IR). In our simulations, one iteration represents one day so that 6 months, the temporal unit over which our empirical diffusion rates were computed (see figures 1-2), amount to 180 iterations. The simulations last for 52 (Indian case) or (32) semesters, the temporal window for which we have empirical data, namely from 1987 (Indian case) or 1997 (Kenyan case) to the second half of 2013. To get the total number of interactions for a given model variant, it suffices to multiply the interaction rate by 180 (the number of days in one semester) by 52 (the total number of semesters over which the simulation unfolds). For simulations for the Indian case, when the interaction rate is equal to $1,2,3$ or 4 , this means that 1,2, 3 or 4 adopter/potential adopter pairs interact at each iteration. When the interaction rate is equal to 0.25 or 0.5 , this means that, at each iteration, there is only a probability of 0.25 or 0.5 that a pair of adopter/potential adopter gets in contact. For simulations for the Kenyan case, a lower number of adopter/potential adopter pairs to be sampled at each iteration is required because the Kenyan potter population is smaller, the diffusion process spans over a shorter while, and pottery only occupies a month a year. In particular, when the interaction rate is equal to 0.005 , this means that, at each iteration, there is only a probability of 0.005 that a pair of adopter/potential adopters gets in contact, thus implying that, over a semester (180 iterations), only 1 interaction takes place. Following the same reasoning, readers can deduce that $0.02,0.03,0.05,0.09$, and 0.18 respectively correspond to $4,6,10,16$, and 32 interactions per semester. 